\title{
Intoxicação espontânea por Senecio brasiliensis (Asteraceae) em ovinos no Rio Grande do Sul ${ }^{1}$
}

\begin{abstract}
Marcia R. S. Ilha ${ }^{2}$, Alexandre P. Loretti ${ }^{3}$, Severo S. Barros ${ }^{4}$ e Claudio S. L. Barros ${ }^{5}$
ABSTRACT.- Ilha M. R.S., Loretti A.P., Barros S.S. \& Barros C.S.L. 2001. [Spontaneous poisoning in sheep by Senecio brasiliensis (Asteraceae) in southern Brazil] Intoxicação espontânea por Senecio brasiliensis (Asteraceae) em ovinos no Rio Grande do Sul. Pesquisa Veterinária Brasileira21(3):123-138. Depto Patologia, Universidade Federal de Santa Maria, 97105-900 Santa Maria, RS, Brazil. E-mail: ilha76@mailcity.com

An outbreak of spontaneous Senecio brasiliensis poisoning in grazing sheep in the county of Mata, Rio Grande do Sul, southern Brazil, is described. The disease occurred on one farm in middle January 1997. Fifty-one (54.25\%) out of 94 sheep were affected, and 50 animals (53.2\%) died. This flock of sheep had been grazing for approximately 7 months (from June 1996 to January 1997) in paddocks heavily infested with $S$. brasiliensis. Clinical signs included photodermatitis, progressive emaciation, apathy, weakness, neurological signs such as drownsiness, aimless walking and unsteady gait, jaundice and hemoglobinuria. There was amelioration of the skin lesions in those sheep that developed hepatogenous photosensitization. Main necropsy findings in 9 sheep included small, firm, tan or greenish liver with few to numerous small, yellowish, well-circumscribed nodules measuring up to $3 \mathrm{~mm}$ in diameter and randomly scattered throughout the hepatic parenchyma. There was also marked distension of the gallbladder which contained large amounts of inspissated, dark green bile and straw-colored cavitary effusions (hydropericardium and ascitis). Five sheep developed lethal acute hemolytic crisis, secondary to massive release into the blood stream of copper accumulated in the liver (hepatogenous chronic copper poisoning). Apart from the aforementioned liver lesions, other gross findings in those animals included severe and diffuse jaundice, dark brown urine (hemoglobinuria) and swollen, friable, finely stippled or diffusely dark kidneys. The main histopathological findings included hepatomegalocytosis, biliary ductal proliferation (bile duct hyperplasia) and moderate periportal fibrosis. The portal triads were infiltrated with variable numbers of mononuclear cells. There was heavy accumulation of brownish pigment in macrophages identified as ceroid or copper with PAS and rhodanine stainings, respectively. Those ceroid and copper-laden macrophages were scattered on the remnant hepatic parenchyma or formed small aggregates in the portal triads. Main histopathological findings in the kidneys of 5 sheep, that developed fatal hepatogenous chronic copper poisoning, included tubular nephrosis, accumulation of hemoglobin and hemosiderin in epithelial tubular cells and hemoglobin casts (hemoglobinuric nephrosis). Morphological evidence of hepatic encephalopathy included spongy degeneration (status spongiosus) of the
\end{abstract}

\footnotetext{
${ }^{1}$ Aceito para publicação em 24 de agosto de 2001.

Trabalho financiado pelo Programa de Apoio a Núcleos de Excelência (PRONEX). Parte da dissertação de Mestrado do primeiro autor. Defendida no Programa de Pós-Graduação em Medicina Veterinária, Área de Concentração em Patologia Veterinária, Centro de Ciências Rurais, Universidade Federal de Santa Maria (UFSM), em 10 de agosto de 2001.

${ }^{2}$ Programa de Pós-Graduação em Medicina Veterinária, Mestrado, Universidade Federal de Santa Maria (UFSM), 97105-900 Santa Maria, RS. E-mail: ilha76@mailcity.com.br
}

\footnotetext{
${ }^{3}$ Setor de Patologia Veterinária, Depto Patologia Clínica Veterinária, Faculdade de Veterinária, Universidade Federal do Rio Grande do Sul (UFRGS), Av. Bento Gonçalves 9090, Caixa Postal 15094, Bairro Agronomia, Porto Alegre, RS 91540-000. E-mail: aloretti@hotmail.com

${ }^{4}$ Pesquisador visitante do CNPq, Depto Patologia Animal, Faculdade de Veterinária, Universidade Federal de Pelotas (UFPel), Pelotas, RS 96010-900. E-mail: severo@ufpel.tche.br

${ }^{5}$ Depto Patologia, Universidade Federal de Santa Maria (UFSM), 97105900 Santa Maria, RS. E-mail: cslb@sm.conex.com.br.
} 
cerebral white matter. Ultrastructural changes in the liver of affected sheep included degenerative hepatocellular changes of varying severity. There was accumulation of numerous lipid droplets in the cytoplasm of the hepatocytes and lysosomes containing substances of high electron-density that corresponded to ceroid-lipofuscin in most of the cases. In addition, there was mild swelling of the rough endoplasmic reticulum and moderate hyperplasia of the smooth endoplasmic reticulum in some areas of the cytoplasm of the hepatocytes. Proximal convoluted tubular epithelial cells showed intracellular edema and a variety of mitochondrial degenerative changes. These included disarrangement and breakup of cristae, finely granular matrix, accumulation of lipid globules and rupture of the membranes in a few cases. Many epithelial tubular cells displayed substances of high electron-density within lysosomes. Chemical analysis of copper in liver and kidney samples of affected sheep revealed high concentrations varying from $369 \mathrm{ppm}$ to $1248 \mathrm{ppm}$ in the liver and ranging from $152 \mathrm{ppm}$ to $687 \mathrm{ppm}$ in the kidneys (dry matter). The diagnosis of Senecio brasiliensis poisoning was based on epidemiological data, clinical signs, necropsy findings, histological lesions and laboratory data.

INDEX TERMS: Senecio brasiliensis, Asteraceae, diseases of sheep, poisonous plants, copper toxicosis, pathology.

RESUMO.- Descreve-se a ocorrência de um surto de intoxicação espontânea por Senecio brasiliensis em ovinos em um estabelecimento do município de Mata, Estado do Rio Grande do Sul, em meados de janeiro de 1997. De um total de 94 ovinos, $51(54,25 \%)$ animais adoeceram e $50(53,2 \%)$ morreram. Esse rebanho permaneceu durante aproximadamente 7 meses (de junho de 1996 a janeiro de 1997) em piquetes de pastagem nativa onde havia grande quantidade de $S$. brasiliensis. $\mathrm{O}$ quadro clínico manifestado pelos animais afetados consistia em fotossensibilização, emagrecimento progressivo, apatia, fraqueza, perturbações neurológicas como depressão, andar a esmo e desequilibrado, icterícia e hemoglobinúria. Houve melhora das lesões de pele naqueles ovinos que desenvolveram fotossensibilização hepatógena depois que foram retirados do sol. As principais lesões macroscópicas observadas em 9 dos 10 ovinos necropsiados incluíam fígado diminuído de tamanho, firme, difusamente marrom amarelado ou esverdeado, com quantidades variáveis de nódulos de 1-3 mm de diâmetro, bem circunscritos, salientes na cápsula, amarelados, distribuídos aleatoriamente por todo o parênquima. A vesícula biliar estava repleta e preenchida por bile verde escura e espessa. Havia também derrames cavitários (hidropericárdio e ascite). Crise hemolítica aguda fatal associada à intoxicação crônica hepatógena por cobre foi observada em cinco ovinos. Além das lesões hepáticas macroscópicas já mencionadas, foi observada icterícia generalizada da carcaça, rins tumefeitos, friáveis, difusamente escurecidos ou com fino pontilhado enegrecido; a urina era marrom escura (hemoglobinúria). As principais lesões microscópicas foram observadas no fígado e consistiam em hepatomegalocitose, proliferação de ductos biliares (hiperplasia ductal) e fibrose periportal moderada acompanhada de infiltrado inflamatório mononuclear. Macrófagos carregados de pigmento acastanhado formavam aglomerados nas tríades portais ou estavam dispersos entre os hepatócitos remanescentes. O material armazenado no citoplasma desses macrófagos correspondia a ceróide e cobre, positivo nas técnicas de PAS e rodanina, respectivamente. Nos rins de cinco animais, havia nefrose hemoglobinúrica caracterizada por degeneração e necrose do epitélio tubular, presença de hemoglobina e hemossiderina no citoplasma das células epiteliais dos túbulos contorcidos e cilindros de hemoglobina na luz tubular. Evidência morfológica de encefalopatia hepática incluía degeneração esponjosa (status spongiosus) da substância branca do encéfalo. Achados ultra-estruturais no fígado incluíam graus variáveis de degeneração hepatocelular caracterizada pelo acúmulo de numerosas gotas lipídicas no citoplasma das células hepáticas e presença de lisossomos carregados de material eletrodenso que, na maioria dos casos, correspondia à lipofuscina-ceróide. Adicionalmente, havia discreta dilatação do retículo endoplasmático rugoso e moderada hiperplasia do retículo endoplasmático liso em algumas regiões do citoplasma dos hepatócitos. No epitélio dos túbulos contorcidos proximais do rim foi observado edema intracelular e diversas alterações mitocondriais de caráter degenerativo que inclúam tumefação, desorganização e ruptura das cristas, matriz finamente granular, acúmulo de gotículas de gordura e ruptura das membranas em alguns casos. Lisossomos contendo material fortemente eletrodenso foram observados em muitas células tubulares renais. $\mathrm{O}$ exame laboratorial de fragmentos de fígado e rim dos ovinos afetados revelou níveis elevados de cobre que variaram respectivamente de $369 \mathrm{ppm}$ a $1248 \mathrm{ppm}$ e $152 \mathrm{ppm}$ a $687 \mathrm{ppm}$ com base na matéria seca. $O$ diagnóstico de intoxicação por Senecio brasiliensis baseou-se em dados epidemiológicos, clínicos, de necropsia, histopatológicos e laboratoriais.

TERMOS DE INDEXAÇÃO: Senecio brasiliensis, Asteraceae, doenças de ovinos, plantas tóxicas, intoxicação por cobre, patologia.

\section{INTRODUÇÃO}

Senecio spp pertencem às plantas tóxicas mais importantes do Rio Grande do Sul e a intoxicação por Senecio brasiliensis tem causado grandes prejuízos econômicos para a bovinocultura da região Sul do país (Méndez 1993a). Assim, os esforços de profissionais de diversas áreas têm se concentrado na realização de estudos multidisciplinares visando o desenvolvimento de estratégias eficazes de controle e profilaxia da intoxicação por Senecio spp em nosso Estado. Procedimentos consagrados como o combate da planta em 
pastos nativos através da utilização de ovinos (Méndez 1993a), estudo histológico de biópsias hepáticas de bovinos clinicamente saudáveis em rebanhos acometidos por seneciose (Barros et al. 1992), rodízio de pastagens (Méndez 1993a) e suplementação mineral adequada (Vardiman 1952) vêm sendo aliados a técnicas mais recentes na tentativa de diminuir sobremaneira a prevalência da toxicose em nossos rebanhos. Essas incluem o emprego de insetos no controle da planta (Klitzke \& Trigo 2000), a transferência de flora ruminal de ovinos para bovinos com o objetivo de conferir resistência a esses últimos aos efeitos nocivos das pirrolizidinas (Johnston et al. 1998) e a aplicação de herbicidas (Forsyth 1979).

É sabido que os ovinos são bastante resistentes à ação dos alcalóides pirrolizidínicos presentes em Senecio spp, de modo que podem controlar a planta consumindo-a sem, na maioria das vezes, adoecer (Méndez 1993a). A resistência dessa espécie doméstica à ação hepatotóxica das pirrolizidinas está associada a peculiaridades de sua flora ruminal (Craig et al. 1992) e aos sistemas enzimáticos do fígado, o que resulta em uma extraordinária capacidade de detoxificação dos alcalóides pirrolizidínicos (Huan et al. 1998). O uso de lotações iguais ou superiores 0,43 ovinos/ha em pastoreio contínuo em áreas invadidas por Senecio spp controla a planta de forma eficiente (Soares et al. 2000). Dados a respeito dos possíveis riscos enfrentados por rebanhos ovinos durante essa prática são conflitantes. A maior parte dos autores não enfatiza os aspectos negativos dessa medida profilática naquelas situações em que não são respeitadas as lotações de ovinos e os períodos de pastoreio recomendados e preconizam o emprego indiscriminado de ovelhas no combate aos senécios (Dollahite 1972). No entanto, alguns pesquisadores alertam para os possíveis prejuízos econômicos que esse manejo pode trazer para os criadores, uma vez que rebanhos ovinos mantidos durante vários anos em áreas severamente invadidas por plantas que possuem pirrolizidinas podem adoecer após ingerir grande quantidade de pirrolizidinas (Seaman 1985, Seaman \& Dixon 1989). Experimentos a campo em que ovelhas mantidas durante várias estações em piquetes com grande quantidade dessas plantas desenvolveram um quadro clínico-patológico semelhante aos casos de seneciose espontânea corroboram essa hipótese (Bull et al. 1968, Seaman et al. 1989, Peterson et al. 1992).

Há relatos de surtos de seneciose em rebanhos ovinos causados pelo consumo de Senecio cineraria no Iraque (Forsyth 1979) e S. sanguisorbae no México (Rosiles \& Paasch 1982). Na Austrália, S. madagascariensis esteve envolvido em um surto de intoxicação por pirrolizidinas em ovinos (Seaman 1987). Em algumas regiões da Austrália, a ingestão de Echium plantagineum e Heliotropium europaeum é considerada a maior causa de perdas de ovinos pela ingestão de plantas contendo pirrolizidinas (St George-Grambauer \& Rac 1962, Bull et al. 1968, Seaman 1985, 1987). Intoxicação por em ovinos por Senecio spp também tem sido descrita na África do Sul (Kellerman et al. 1988) e Nova Zelândia (Bull et al. 1968). Entretanto, dados a respeito dos aspectos epidemiológicos, clínicos e patológicos da intoxicação espontânea por Senecio spp em ovinos são escassos. A necessidade do conhecimento do quadro clínico, anatomopatológico e ultra-estrutural dessa toxicose em ovinos tornou oportuna a elaboração de um estudo pormenorizado descrevendo a ocorrência de casos espontâneos de hepatopatia tóxica crônica em um rebanho de ovinos no Estado do Rio Grande do Sul associada à ingestão de S. brasiliensis. A morfologia e a patogenia da lesão hepática e o quadro clínico-patológico observados são discutidos e comparados com outros relatos de intoxicação espontânea e experimental por plantas que contêm alcalóides pirrolizidínicos em ovinos já descritos na literatura. São consideradas as principais doenças que devem ser incluídas no diagnóstico diferencial da intoxicação por $S$. brasiliensis em ovinos, em particular aquelas que ocorrem em nosso país.

\section{MATERIAL E MÉTODOS}

Os dados epidemiológicos e sinais clínicos foram obtidos em uma visita realizada ao estabelecimento onde ocorreu o surto e por informações fornecidas pelo proprietário e pelo veterinário do local. $\mathrm{Na}$ ocasião dessa visita, um dos ovinos doentes (Ovino 1) foi sacrificado, necropsiado e fragmentos de fígado, rim, encéfalo e pele foram coletados em formol a $10 \%$. Outros nove ovinos afetados nessa propriedade foram enviados ao Setor de Patologia Veterinária, Departamento de Patologia da Universidade Federal de Santa Maria (UFSM). Esses ovinos eram mantidos no Hospital Veterinário (HV) da UFSM em baias de alvenaria e recebiam feno de alfafa e água à vontade. Diariamente eram observados os seguintes parâmetros: apetite, disposição em movimentar-se, coloração das mucosas e aspecto das fezes e da urina. Biópsias hepáticas foram realizadas nos Ovinos 46, 115, 136 e 19, respectivamente 40, 89, 107 e 310 dias antes da morte dos animais. As biópsias de fígado foram processadas para microscopia de luz e eletrônica de transmissão.

Necropsias foram realizadas nos animais que morreram espontaneamente (Ovinos 46, 115 e 136) ou que foram sacrificados (Ovinos 2, 5, 9, 11, 12 e 19). O encéfalo e fragmentos de fígado, de rim e de outros órgãos foram colhidos e fixados em formol a $10 \%$.

Fragmentos de rim e de fígado de sete ovinos clinicamente saudáveis foram colhidos em um matadouro localizado no município de São Lourenço do Sul e fixados em formol a $10 \%$ para controle histológico e controle de níveis de cobre. Os tecidos coletados nas necropsias dos animais afetados, as biópsias hepáticas e os fragmentos de fígado e de rim dos animais controle foram processados rotineiramente para microscopia de luz e corados pela hematoxilina e eosina (HE). As seguintes técnicas histoquímicas foram empregadas em cortes parafinados: (a) tricrômico de Masson modificado por Goldner para colágeno em cortes de fígado, incluindo o material das biópsias hepáticas; (b) Van Gieson modificado para hemoglobina em cortes de rim; (c) rodanina para cobre $(\mathrm{Cu})$, PAS para ceróide e Perls para ferro em cortes de fígado e de rim. Fragmentos de fígado e de rim de três animais (Ovinos 9, 11 e 12) também foram processados para microscopia eletrônica de transmissão.

Foi realizada dosagem de cobre, expressa em matéria seca, de fragmentos fixados em formol de rim de cinco animais (Ovinos 9, 11, 12, 19 e 46) e de fígado de oito animais (Ovinos 2, 5, 9, 11, 12, 19, 46 e 115) afetados e fragmentos de rim de cinco animais controle e fragmentos de fígado de sete animais controle, também fixados em formol. As dosagens foram realizadas pela técnica de espectrofotometria de absorção atômica, utilizando-se digestão com ácido nítrico sob pressão para o preparo da amostra e um espectrofotômetro de absorção atômica - Perkin Elmer 3300, como equipamento. 
Os ovinos acompanhados clinicamente e necropsiados foram divididos em grupos de acordo com as principais alterações clínicopatológicas apresentadas por cada um deles: Grupo I- ovinos que desenvolveram quadro de intoxicação primária por pirrolizidinas ou que não apresentaram sinais clínicos óbvios (Ovinos 12, 19, 46, 115 e 136) e Grupo II- ovinos que apresentaram quadro de intoxicação hepatógena por cobre secundária à ação das pirrolizidinas (Ovinos 1, 2, 5, 9 e 11). Os ovinos incluídos no Grupo II são os que apresentaram alterações macroscópicas e histológicas de nefrose hemoglobinúrica.

As alterações histológicas hepáticas foram classificadas quanto à intensidade e distribuição nos ovinos dos Grupos I e II. As alterações microscópicas foram graduadas de 1 (discreta) a 4 (acentuada) de acordo com a intensidade das lesões. Esses dados foram anotados de acordo com a média da percepção subjetiva de dois patologistas que examinaram as lâminas. $O$ número de pseudoinclusões intranucleares nos hepatócitos foi estabelecido a partir da média do exame de 20 campos de maior aumento (CMA) em dois cortes histológicos de fígado de cada um dos animais. Para a quantificação do grau de fibrose hepática foram observadas lâminas coradas com HE e Masson. A observação do $\mathrm{Cu}$ hepático foi realizada pela técnica de rodanina confrontando esses dados com os das análises de espectrofotometria de absorção atômica de fragmentos de fígado.

\section{RESULTADOS}

\section{Epidemiologia}

A intoxicação ocorreu no município de Mata, na região central do Rio Grande do Sul, a aproximadamente $400 \mathrm{~km}$ de Porto Alegre, em meados de janeiro de 1997. O rebanho era formado por 94 ovinos que ocupavam piquetes de pastagem nativa onde a planta predominante era Senecio brasiliensis. Cinqüenta e um ovinos adoeceram (54,25\%) e cinqüenta $(53,2 \%)$ morreram. Todos os animais eram nativos da propriedade. Das 50 mortes, 42 ocorreram no próprio estabelecimento de dezembro de 1996 a janeiro de 1997 . Nove ovinos foram trazidos para as dependências do HV da UFSM e mantidos aí até a morte, espontânea ou por eutanásia, até 12 meses após a ocorrência do surto.

O rebanho deste surto havia sido alocado, a partir de junho de 1996, por aproximadamente três meses, em um potreiro de 25 ha. (3,76 ovinos/ha). De setembro a dezembro de 1996, esses ovinos foram transferidos para outro piquete com aproximadamente 60 ha onde ficaram juntos com 60 bovinos. Em dezembro do mesmo ano, morreram cerca de 15 ovelhas. A partir dessa época, todos os ovinos foram colocados em um terceiro piquete também de 60 ha, onde ocorreram as demais mortes. Nos três piquetes havia grande quantidade de exemplares de $S$. brasiliensis com sinais de terem sido consumidos. A partir de setembro de 1996 a lotação de ovinos nesses potreiros correspondia a aproximadamente 1,3 ovino/ha.

Dos ovinos que morreram, dezesseis tinham menos de 1 ano, dezenove tinham entre um e dois anos e os quinze restantes tinham acima de dois anos. As percentagens de animais afetados em relação a cada faixa etária eram de $100 \%$, $54,28 \%$ e $34 \%$, respectivamente. Esses ovinos não recebiam qualquer tipo de suplementação mineral na dieta. Análises químicas da pastagem, de $S$. brasiliensis e do solo para níveis de cobre, molibdênio, sulfatos e outros minerais não foram realizadas.

\section{Sinais clínicos}

O espectro de sinais clínicos manifestado pelos ovinos intoxicados era consistente com o de insuficiência hepática que, em parte dos casos, estava complicada por crises hemolíticas agudas devido ao acúmulo excessivo de cobre no fígado. Ocorria fotodermatite, perda de lã, icterícia, fraqueza e andar cambaleante.

Dos nove ovinos trazidos para o Hospital Veterinário da UFSM, a maior parte deles apresentava lesões de fotossensibilização. Essas caracterizavam-se por crostas no focinho, ao redor dos olhos e na face externa das orelhas. Essas lesões crostosas, quando destacadas, revelavam pele avermelhada e ulcerada (Fig. 1). Adicionalmente, o Ovino 11 apresentava marcada perda de lã no dorso. O quadro clínico de fotossensibilização regrediu consideravelmente alguns dias após esses animais terem sido colocados em baias cobertas. Um dos ovinos parcialmente recuperado das lesões de fotodermatite foi novamente exposto ao sol por períodos diários de 1 a 2 horas por aproximadamente uma semana sem recrudescimento das lesões cutâneas.

Nos Ovinos 46, 115 e 136 (Grupo I), o quadro clínico caracterizava-se por sinais inespecíficos como apatia, anorexia e emagrecimento progressivo. Esses animais permaneciam em estação e com a cabeça baixa por longos períodos ou em decúbito esternal. Quando tocados, tinham dificuldade para se levantar, manifestando sinais de fraqueza. A evolução do quadro clínico variou de 1 a 3 semanas. Todos esses animais tiveram morte espontânea. Esses ovinos permaneceram de 4 a 6 meses nas dependências do HV da UFSM. O Ovino 19 (Grupo I) não apresentou qualquer sinal clínico durante o período em que permaneceu nessas instalações (cerca de 1 ano).

Quatro dos nove ovinos adoeceram (Grupo II, Ovinos 2, 5, 9 e 11) após 3 a 28 dias da chegada ao HV da UFSM. O quadro clínico manifestado por esses animais consistiu inicialmente em anorexia, apatia e emagrecimento progressivo. Na fase final da doença foram observados icterícia, hemoglobinúria, sinais nervosos, fraqueza, decúbito esterno-abdominal ou lateral por períodos prolongados e respiração ofegante. Esses sinais clínicos tiveram aparecimento súbito. O curso clínico da enfermidade nesses ovinos foi de aproximadamente 9 dias. Não foi observada icterícia no Ovino 5. Todos os animais desse grupo foram sacrificados in extremis.

Os sinais clínicos observados no Ovino 12 incluíam anorexia, depressão e perda da condição corporal. Icterícia moderada e sinais clínicos nervosos foram observados após esse animal ter sido submetido a uma situação de estresse. Esse ovino foi sacrificado in extremis após 30 dias da chegada ao HV.

Nos Ovinos 11 e 12 ocorreram perturbações neurológicas que incluíam depressão, desequilíbrio, dificuldade de permanecer em estação, andar cambaleante, a esmo e em linha reta, incoordenção e colisão contra obstáculos. Devido à grande instabilidade, esses animais assumiam posições anômalas, tais 

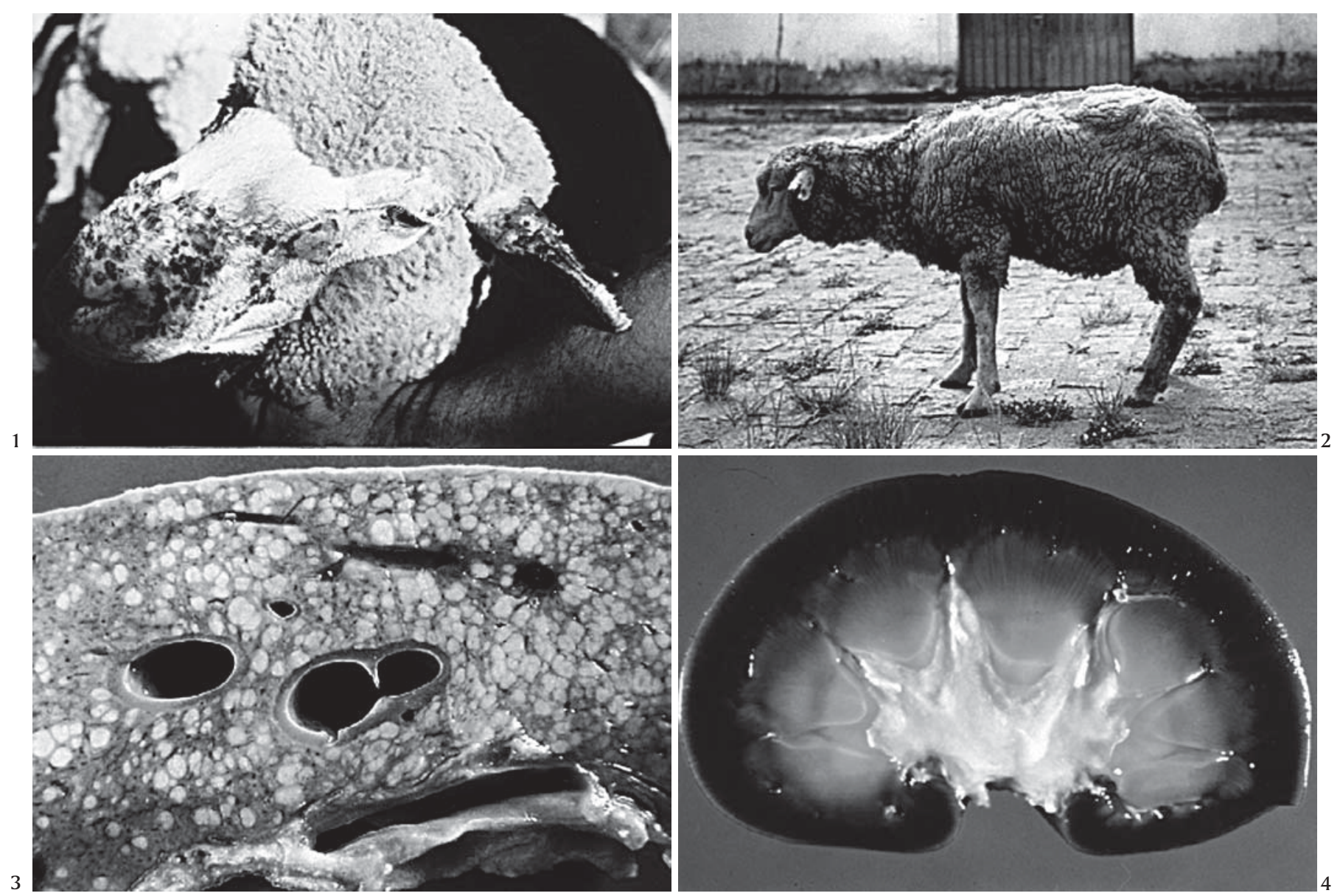

Fig. 1. Intoxicação espontânea por Senecio brasiliensis (Ovino 1). Lesões de fotossensibilização caracterizadas por crostas no focinho, ao redor dos olhos e na face externa das orelhas.

Fig. 3. Intoxicação espontânea por S. brasiliensis (Asteraceae) (Ovino 12). No fígado (fixado em formol), há múltiplos nódulos de regeneração brancos, de 1 a $3 \mathrm{~mm}$ de diâmetro, bem circunscritos, distribuídos aleatoriamente na superfície de corte.

como permanência com os membros lateralmente afastados e a cabeça baixa (posição de cavalete) ou com os membros bem próximos uns dos outros, balançando o corpo para frente e para trás. Esses animais apoiavam a cabeça contra objetos e mantinham grande parte da face imersa na água dos bebedouros. O Ovino 11 permanecia em estação, imóvel, totalmente alheio ao ambiente, sonolento e com ptose palpebral (Fig. 2). Em algumas ocasiões, investia à aproximação das pessoas.

\section{Achados de necropsia}

A principal lesão macroscópica foi observada no fígado e ocorreu em todos os ovinos, com exceção do Ovino 19. À necropsia, o fígado estava diminuído de volume, firme e difusamente marrom-amarelado ou esverdeado. Nas superficies natural e de corte, foram observados nódulos de regeneração claros, salientes, bem delimitados, de um a três milímetros de diâmetro e de distribuição aleatória (Fig. 3). Li-

Fig. 2. Intoxicação espontânea por S. brasiliensis (Ovino 11). Animal alheio ao ambiente, apático e magro.

Fig. 4. Intoxicação espontânea por S. brasiliensis (Ovino 2). Rim, superfície de corte. $\mathrm{O}$ córtex renal está difusamente enegrecido.

nhas brancas e delgadas se entrecruzavam no parênquima hepático conferindo à superfície de corte um padrão reticulado. No fígado de alguns ovinos, havia placas esbranquiçadas, bem delimitadas, levemente salientes, que correspondiam a espessamentos focais da cápsula hepática. No Ovino 12, foi observada icterícia leve. Com exceção dos Ovinos 1, 5 e 9, havia acentuada distensão da vesícula biliar que estava repleta de bile verde escura e espessa. No Ovino 2, além das lesões já mencionadas, havia discreto edema da parede da vesícula biliar. No Ovino 136, os linfáticos associados à parede da vesícula biliar estavam dilatados e tortuosos. Nos ovinos do Grupo II, além das lesões hepáticas já mencionadas, os rins estavam tumefeitos, friáveis, marromescuros ou enegrecidos (Fig. 4). Em alguns casos havia um fino pontilhado enegrecido distribuído aleatoriamente nas superfícies capsular e de corte, principalmente na região cortical (nefrose hemoglobinúrica). A urina desses animais era âmbar ou marrom-escura (hemoglobinúria). Com exce- 
Quadro 1. Intoxicação espontânea por Senecio brasiliensis em ovinos. Principais achados de necropsia

\begin{tabular}{cll}
\hline $\begin{array}{c}\text { Ovino } \\
\text { no. }\end{array}$ & \multicolumn{1}{c}{ Fesícula biliar } \\
\hline $\begin{array}{l}\text { Grupo I - Intoxicação primária por pirrolizidinas } \\
12\end{array}$ & $\begin{array}{l}\text { Diminuído, firme, marrom-claro, nódulos de } \\
1 \text { a } 3 \text { mm amarelados nas superfícies capsu- } \\
\text { lar e de corte }\end{array}$ & $\begin{array}{l}\text { Repleta de bile } \\
\text { espessa }\end{array}$ \\
46 & $\begin{array}{l}\text { Diminuído, firme, marrom-amarelado, áreas de } \\
\text { espessamento da cápsula, nódulos de } 2 \text { mm } \\
\text { nas superfícies capsular e de corte. }\end{array}$ & $\begin{array}{l}\text { Repleta de bile espes- } \\
\text { sa e verde-escura }\end{array}$ \\
115 & $\begin{array}{l}\text { Diminuído, firme, marrom-amarelado, nódulos } \\
\text { de } 1 \text { a } 3 \text { mm nas superfícies capsular e de corte. }\end{array}$ & $\begin{array}{l}\text { Repleta de bile espes- } \\
\text { sa e verde-escura }\end{array}$ \\
136 & $\begin{array}{l}\text { Diminuído, firme, marrom-claro, áreas de espes- } \\
\text { samento da cápsula. }\end{array}$ & $\begin{array}{l}\text { Distendida, vasos lin- } \\
\text { fáticos da parede dila- } \\
\text { tados }\end{array}$
\end{tabular}

Grupo II - Intoxicação hepatógena por cobre, secundária à ação das pirrolizidinas

1 Diminuído, firme, marrom-esverdeado

2 Diminuído, firme, marrom-amarelado, áreas de espessamento da cápsula.

Distendida, discreto edema da parede

5 Diminuído, firme, marrom-claro, áreas de espessamento da cápsula.

9 Diminuído, firme, amarelado, nódulos de $2 \mathrm{~mm}$ nas superfícies capsular e de corte.

11 Diminuído, firme, marrom-claro, nódulos de 1 a $3 \mathrm{~mm}$ nas superfícies capsular e de corte.

Repleta de bile verde-escura e grumosa
Tumefeitos,
levemente
pálidos

Rins

Urina

Icterícia Edema do Hidrope- Ascite mesentério ricárdio

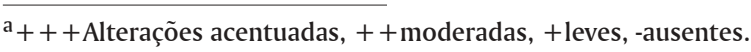

ção do Ovino 5, todos os demais animais desse grupo apresentavam icterícia que variava de leve a acentuada. No Ovino 19, não foram observadas alterações macroscópicas significativas. Os principais lesões macroscópicas de 9 ovinos necropsiados estão relacionadas no Quadro 1.

\section{Achados histológicos}

A principal alteração microscópica, presente em todos os ovinos necropsiados, afetava o fígado de forma difusa e consistia em graus variáveis de fibrose (Fig. 5) caracterizada por proliferação de fibroblastos e colágeno nas regiões periportais. Quando acentuada, a fibrose ocorria em ponte. Em alguns casos, o tecido conjuntivo também estava presente entre os cordões de hepatócitos (fibrose intralobular). Com exceção do Ovino 19, a fibrose periportal estava acompanhada de acentuada proliferação de ductos biliares (hiperplasia ductal). Esses achados histológicos eram mais evidentes nos ovinos do Grupo I. No Ovino 19, havia discreta proliferação de células epiteliais dos ductos biliares.

No fígado de todos os ovinos, foram observados macrófagos contendo quantidades variáveis de pigmento acasta- nhado, levemente amarelado ou, em alguns casos, esvedeado. Essas células ocorriam predominantemente nas áreas periportais e também eram encontradas entre os hepatócitos remanescentes. O pigmento observado no citoplasma dessas células correspondia a ceróide e cobre e corou-se pelo PAS e pela rodanina, respectivamente. Outras alterações histológicas como hepatomegalocitose, pseudo-inclusões nucleares, infiltrado mononuclear periportal e degeneração e necrose hepatocelulares estavam presentes em graus variáveis nos animais dos Grupos I e II. A hepatomegalocitose, caracterizada por aumento de volume das células hepáticas (Fig. 6), era mais acentuada no Ovino 5. As pseudo-inclusões intranucleares correspondiam a inclusões acidofílicas ou anfofílicas (Fig. 7). A frequiência dessas estruturas era de 0,2 a 1,7 por campo de maior aumento. Degeneração e necrose hepatocelulares afetando células individualmente ou pequenos grupos de células foram observadas ocasionalmente e eram mais intensas nos Ovinos 9, 11 e 12 .

Os nódulos claros, salientes, bem delimitados, de 1-3 mm de diâmetro, distribuídos aleatoriamente nas superfícies capsular e de corte do fígado observados à necropsia 


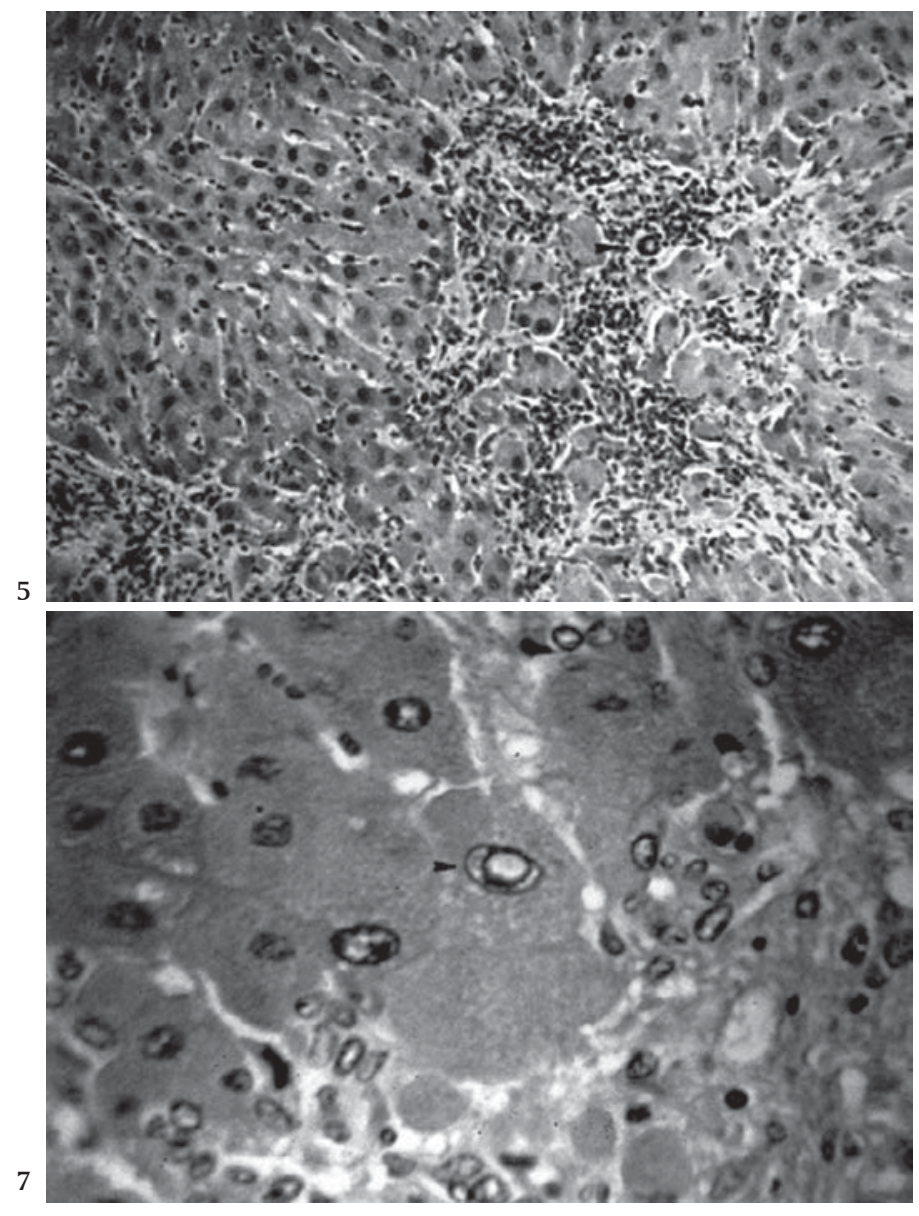

correspondiam, na histologia, a nódulos de regeneração hepatocelular. Consistiam em aglomerados de hepatócitos sem arquitetura definida, i. e., não apresentavam o aspecto de um lóbulo hepático clássico. Esses aglomerados eram circundados por estreita faixa de tecido conjuntivo e pelo parênquima hepático remanescente. Em alguns casos, o citoplasma das células hepáticas que formavam esses nódu-

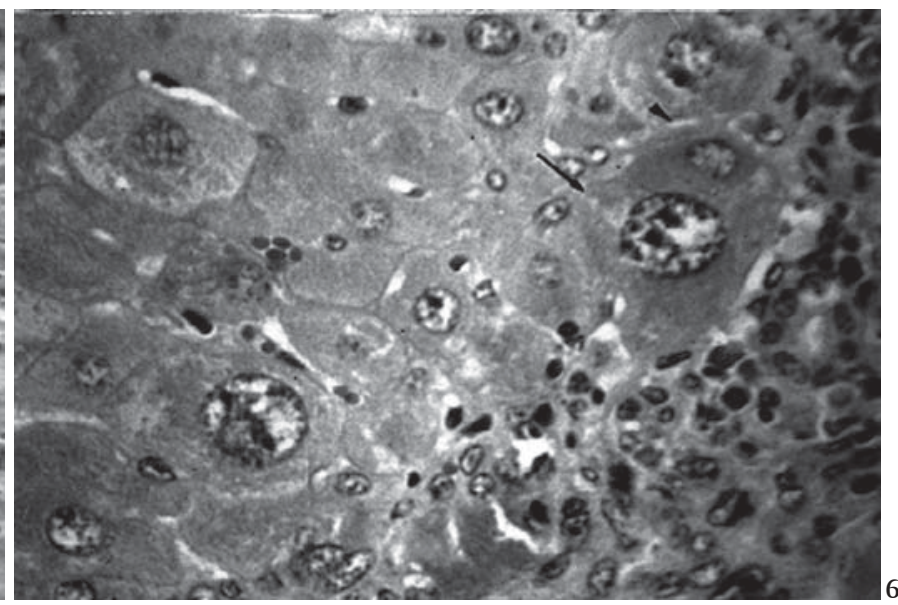

Fig. 5. Intoxicação espontânea por S. brasiliensis ((Ovino 46. Histopatologia do fígado. Proliferação de tecido conjuntivo periportal e dissecando cordões de hepatócitos. Observa-se também proliferação de ductos biliares (cabeça de seta). HE, obj. 25.

Fig. 6. Intoxicação espontânea por S. brasiliensis (Ovino 5). Fígado. Hepatomegalocitose. 0 núcleo e o citoplasma dos hepatócitos estão acentuadamente aumentados de volume (até 6 vezes o tamanho normal). Compare um hepatócito em megalocitose (seta) com um hepatócito de tamanho aproximadamente normal (cabeça de seta). À direita, observam-se fibrose e proliferação de ductos biliares. HE, obj. 40 .

Fig. 7. Intoxicação espontânea por $S$. brasiliensis (Ovino 115). Fígado. Hepatomegalocitose e pseudo-inclusões nucleares (cabeça de seta). As pseudo-inclusões resultam da invaginação da membrana nuclear e seqüestração de uma porção do citoplasma para o interior do núcleo (ver também Fig. 12). HE, obj. 40.

los regenerativos apresentava vacúolos claros e bem delimitados (degeneração gordurosa). Na maior parte dos casos, não foram observadas alterações no tamanho do núcleo ou nas dimensões do citoplasma dos hepatócitos que formavam os nódulos regenerativos. Bilestase intracanalicular foi observada nos Ovinos 2, 9 e 46. Em um caso (Ovino 9), havia lagos de bile entre os grupos de hepatócitos remanescentes.

Quadro 2. Intoxicação espontânea por Senecio brasiliensis em ovinos. Alterações histológicas no fígadoa

\begin{tabular}{|c|c|c|c|c|c|c|c|c|c|c|}
\hline $\begin{array}{l}\text { Ovino } \\
\text { no. }\end{array}$ & Fibrose & $\begin{array}{c}\text { Proliferação } \\
\text { de ductos }\end{array}$ & $\begin{array}{l}\text { Macrófagos } \\
\text { c/ pigmento }\end{array}$ & $\begin{array}{l}\text { Pigmento } \\
\text { de cobre } \\
\text { (Rodanina) }\end{array}$ & $\begin{array}{l}\text { Megalo- } \\
\text { citose }\end{array}$ & $\begin{array}{l}\text { Pseudoin- } \\
\text { clusões/ } \\
\text { CMA }^{c}(400 x)\end{array}$ & $\begin{array}{l}\text { Infiltrado mo- } \\
\text { nonuclear } \\
\text { periportal }\end{array}$ & $\begin{array}{c}\text { Degeneração } \\
\text { e necrose } \\
\text { hepatocelulares }\end{array}$ & $\begin{array}{l}\text { Nódulos de } \\
\text { regeneração }\end{array}$ & Bilestase \\
\hline
\end{tabular}

Grupo II - Intoxicação hepatógena por cobre, secundária à ação de pirrolizidinas

$\begin{array}{ccccccc}1 & ++ & ++ & (+) & (+) & +++ & 0,5 \\ 2 & +++ & +++ & + & ++ & +++ & 0,6 \\ 5 & ++ & ++ & (+) & (+) & +++ & 0,5 \\ 9 & ++ & ++ & +++ & +++ & +++ & 0,5 \\ 11 & +++ & +++ & +++ & + & +++ & 0,4\end{array}$

$\begin{array}{lc}0,5 & +++ \\ 0,6 & + \\ 0,5 & ++ \\ 0,5 & + \\ 0,4 & +++\end{array}$

$\begin{array}{ccc}(+) & - & - \\ + & - & + \\ + & - & - \\ ++ & ++ & ++ \\ +++ & ++ & -\end{array}$

Grupo I - Intoxicação primária por pirrolizidinas

\begin{tabular}{|c|c|c|c|c|c|c|c|c|c|c|}
\hline 12 & +++ & +++ & ++ & $(+)$ & +++ & 0,4 & ++ & ++ & ++ & - \\
\hline 46 & +++ & +++ & ++ & ++ & + & 0,3 & + & $(+)$ & + & + \\
\hline 115 & +++ & +++ & ++ & $\mathrm{NR}^{\mathrm{b}}$ & ++ & 1,7 & ++ & + & ++ & - \\
\hline 136 & +++ & +++ & +++ & + & + & 0,2 & + & $(+)$ & - & - \\
\hline 19 & $(+)$ & $(+)$ & $(+)$ & - & - & - & - & - & - & - \\
\hline
\end{tabular}

$\overline{\mathrm{a}}+++$ Alterações acentuadas, ++ moderadas, + leves, $(+)$ discretas, -ausentes; ${ }^{\mathrm{b}} \mathrm{NR}=$ não realizado; ${ }^{\mathrm{c}} \mathrm{CMA}=$ por campo de maior aumento. 

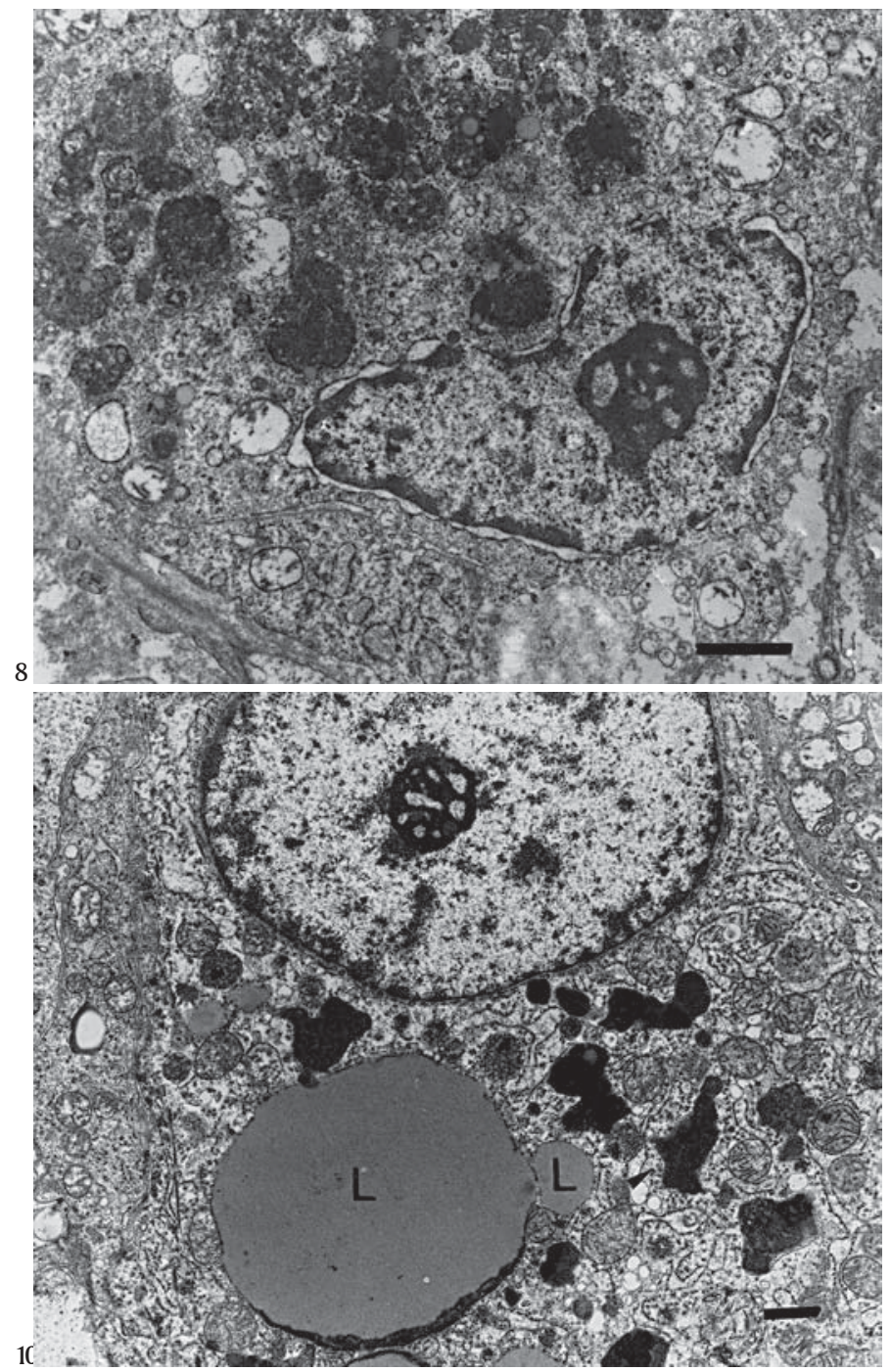

Fig. 8. Intoxicação espontânea por S. brasiliensis (Ovino 9). Fotomicrografia eletrônica, fígado. Hepatócito com numerosos grânulos de lipofuscina-ceróide no citoplasma. Tumefação de mitocôndrias com ruptura e desorganização das cristas. Tumefação da cisterna perinuclear e do retículo endoplasmático rugoso. Barra $=1 \mu \mathrm{m}$.

Fig. 10. Intoxicação espontânea por S. brasiliensis (Ovino 11). Fígado.. Gotas lipídicas (L) de tamanhos variados e estruturas eletrodensas (cabeça de seta) no citoplasma de um hepatócito. Barra $=1 \mu \mathrm{m}$.

As alterações histológicas do fígado dos dez ovinos necropsiados constam do Quadro 2.

O exame histológico das biópsias hepáticas dos Ovinos 46, 115 e 136 revelou fibrose periportal, proliferação das células epiteliais dos ductos biliares, hepatomegalocitose, pseudo-inclusões nucleares e pequeno número de macrófagos, em geral de localização periportal, contendo pigmento acastanhado. Essas lesões eram menos acentuadas, se comparadas às observadas nos fragmentos de fígado colhidos na
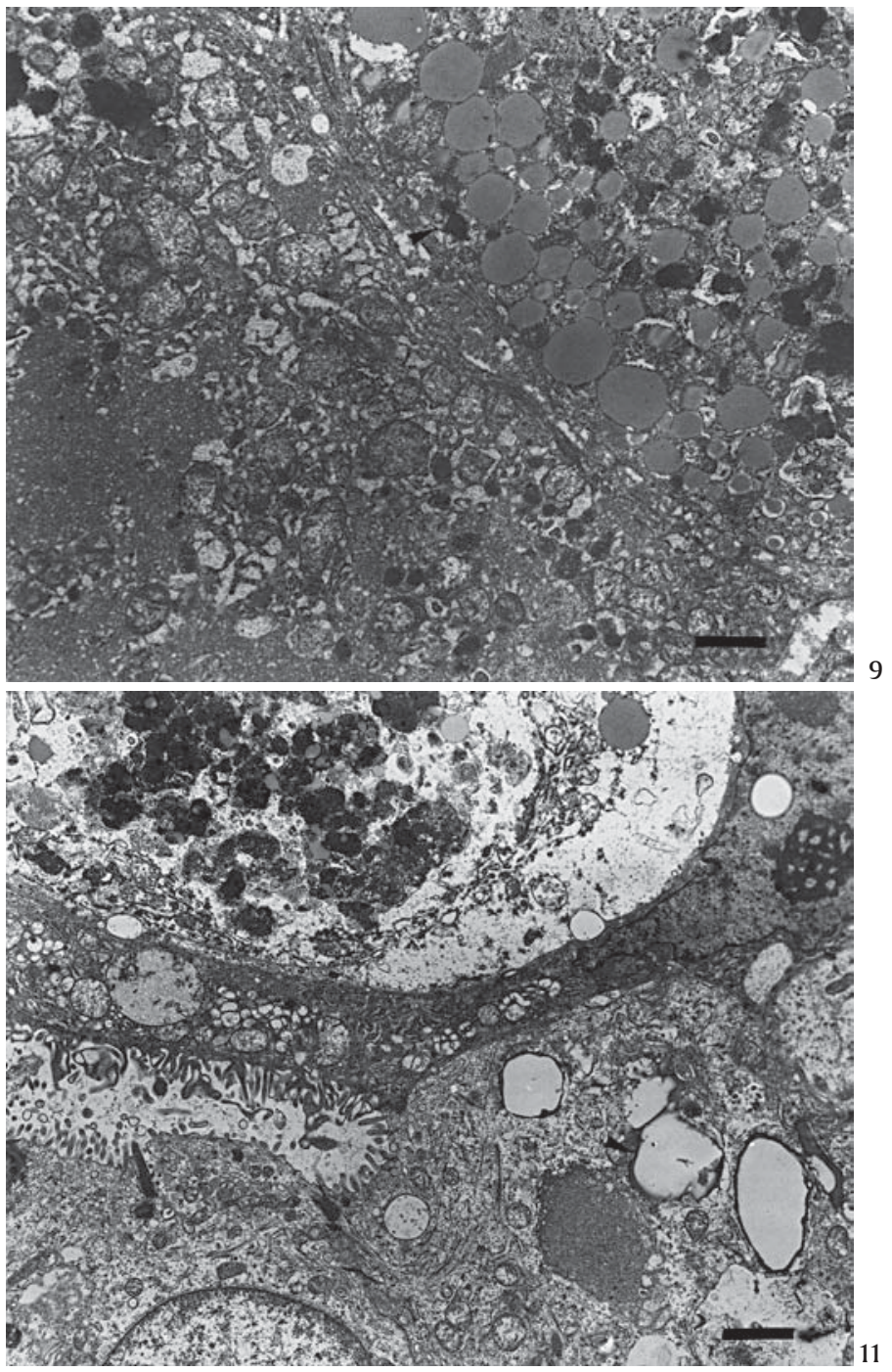

Fig. 9. Intoxicação espontânea por S. brasiliensis (Ovino 11). Fígado. Gotas lipídicas e estruturas eletrodensas de contornos irregulares (cabeça de seta) no citoplasma de hepatócitos. A célula à direita exibe hiperplasia moderada do retículo endoplasmático liso e discreta dilatação do retículo endoplasmático rugoso. Nas mitocôndrias há desorganização das cristas e a matriz está finamente granular. Barra $=1 \mu \mathrm{m}$.

Fig. 11. Intoxicação espontânea por S. brasiliensis (Ovino 9). Fígado. Ducto biliar. Célula epitelial com vacúolos intracitoplasmáticos (cabeça de seta). Ao alto aparece hepatócito com edema do citoplasma e numerosos grânulos de lipofuscina-ceróide. Barra $=2 \mu \mathrm{m}$.

necropsia desses animais. As alterações observadas na biópsia hepática do Ovino 19 eram semelhantes, porém discretas.

Com exceção do Ovino 19, em todos os animais do Grupo I e do Grupo II foram observadas quantidades variáveis de pigmento acastanhado, de aspecto granular, no citoplasma de células epiteliais tubulares renais. Essa alteração era mais intensa nos Ovinos 1,2 e 5 . O pigmento foi positivo na coloração de Perls (ferro) e negativo na coloração de PAS. Em alguns ovinos, havia megalocitose e pseudo-inclusões intranucleares 


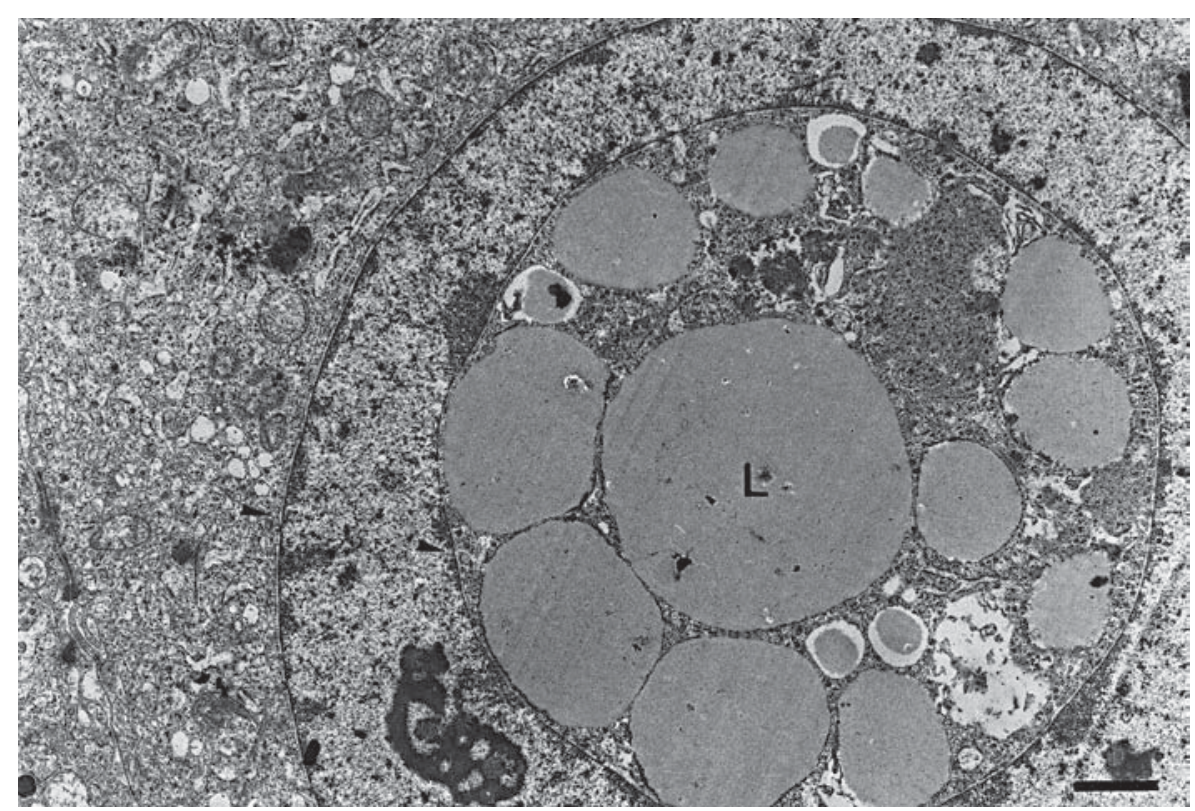

Fig. 12. Intoxicação espontânea por S. brasiliensis (Ovino 9). Fígado. As pseudo-inclusões resultam da invaginação da membrana nuclear e seqüestração de uma porção do citoplasma para o interior do núcleo de hepatócito. No centro do núcleo há porção do citoplasma contendo várias gotículas de lipídio (L) e circundada por membrana nuclear. O nucléolo aparece abaixo à esquerda. Membrana nuclear (cabeças de seta). Barra $=1 \mu \mathrm{m}$.

Quadro 3. Intoxicação espontânea por Senecio brasiliensis em ovinos. Valores da dosagem de cobre ( $\mathrm{ppm}$ ) no fígado e rim dos ovinos afetados e controles

\begin{tabular}{|c|c|c|}
\hline Ovino no. & Fígado & Rim \\
\hline \multicolumn{3}{|c|}{ Ovinos afetados pela intoxicação } \\
\hline 2 & 448 & $\mathrm{NR}^{\mathrm{a}}$ \\
\hline 5 & 854 & $\mathrm{NR}$ \\
\hline 9 & 369 & 152 \\
\hline 11 & 659 & 687 \\
\hline 12 & 455 & 679 \\
\hline 19 & 507 & 406 \\
\hline 46 & 1248 & 593 \\
\hline 115 & 1155 & $\mathrm{NR}$ \\
\hline \multicolumn{3}{|c|}{ Ovinos de controle $(C)$} \\
\hline C 1 & 206 & 163 \\
\hline C 2 & 491 & 113 \\
\hline C 3 & 304 & 127 \\
\hline $\mathrm{C} 4$ & 145 & 310 \\
\hline C 5 & 524 & 143 \\
\hline C 6 & 177 & NR \\
\hline C 7 & 151 & NR \\
\hline
\end{tabular}

em raras células epiteliais tubulares renais. No Ovino 19, não foram observadas alterações histológicas renais. Nos rins dos ovinos do Grupo II, as alterações histológicas consistiam em (a) vacuolização e necrose de células epiteliais dos túbulos contorcidos proximais, (b) presença de esférulas eosinofílicas, homogêneas e refringentes (degeneração em gotas hialinas) no citoplasma de células tubulares, (c) cilindros hialinos e granu- lares acentuadamente eosinofílicos na luz tubular e nos espaços de Bowman e (d) deposição de cálcio na parede e na luz dos túbulos sob a forma de estruturas intensamente basofílicas. Os cilindros hialinos e granulares e as esférulas eosinofílicas presentes nos rins dos ovinos do grupo I se coraram positivamente para hemoglobina pela técnica de Van Gieson.

No encéfalo dos Ovinos 1, 2, 5, 9 e 11 (Grupo I) e Ovinos 12, 46, 115 e 136 (Grupo II) havia evidências morfológicas de encefalopatia hepática caracterizada por degeneração esponjosa (status spongiosus) da substância branca do encéfalo. Essas lesões consistiam em edema das bainhas de mielina na substância branca do cérebro com a formação de múltiplos vacúolos periaxonais bem delimitados que conferiam aspecto esponjoso ao tecido. Essa espongiose era mais acentuada nas regiões do mesencéfalo, tálamo e pedúnculos cerebelares. No córtex cerebral da região do tálamo havia discreta degeneração esponjosa na junção das substâncias branca e cinzenta. Hemossiderose da polpa esplênica foi observada nos Ovinos 11, 46, 115 e 136 .

Nos ovinos que desenvolveram fotodermatite, as lesões cutâneas consistiam em acentuada hiperqueratose paraqueratótica, necrose coagulativa massiva das células epiteliais da epiderme associada a ulcerações focais da epiderme com acúmulo de restos celulares e de neutrófilos. Na derme, havia acentuado infiltrado inflamatório predominantemente mononuclear e, em alguns casos, trombose vascular.

\section{Achados ultra-estruturais}

Na ultra-estrutura do fígado, os hepatócitos exibiam diversos graus de degeneração caracterizados por numerosas gotas 


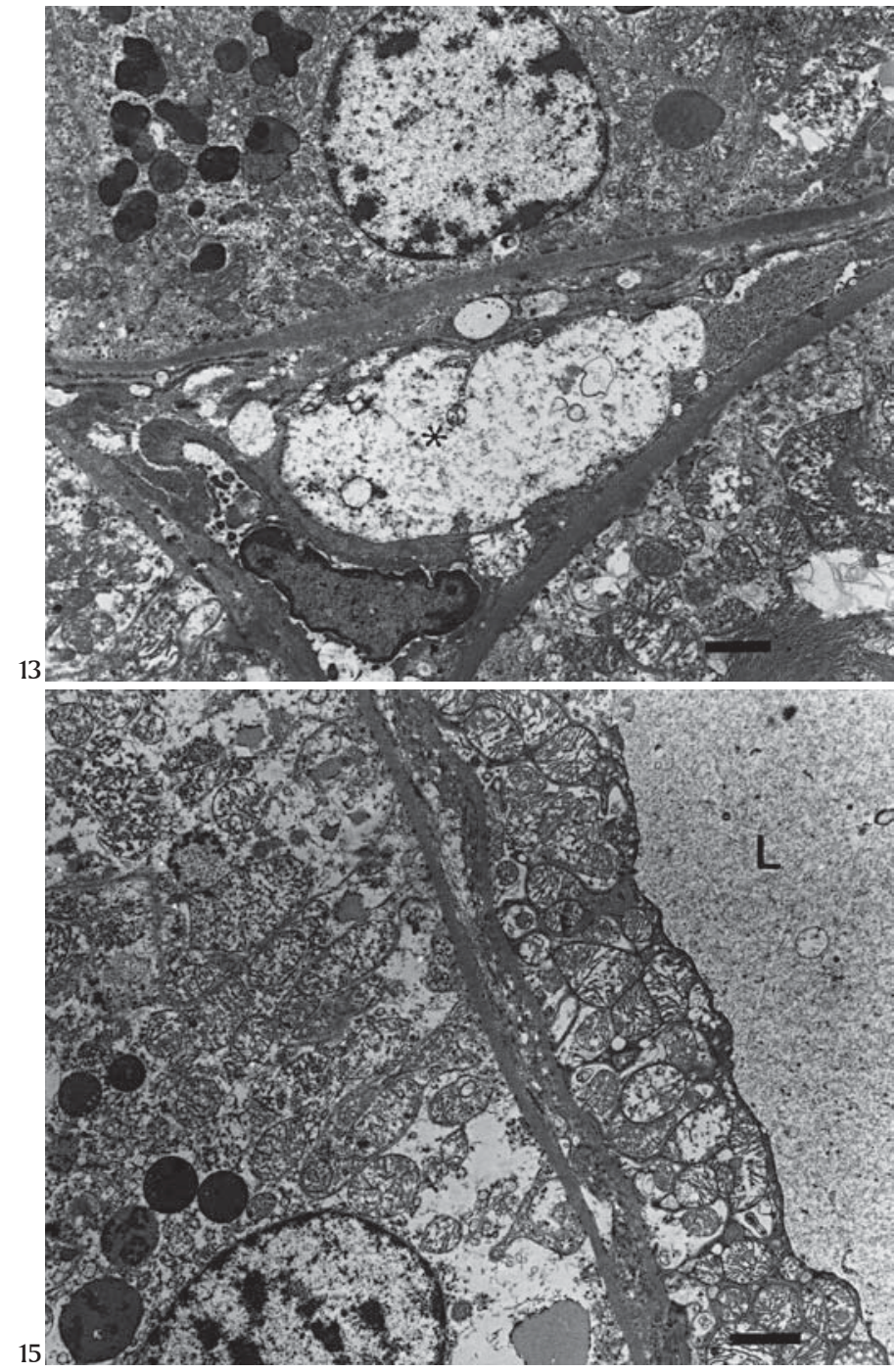

lipídicas e lisossomos carregados de material eletrodenso, muitos deles contendo lipofuscina-ceróide (Fig. 8-11), discreta dilatação do retículo endoplasmático rugoso (Fig. 9) e, em alguns locais, moderada hiperplasia do retículo endoplasmático liso (Fig. 9). Muitos núcleos estavam aumentados de volume, com nucléolo muito evidente e de contornos irregulares. Ocasionalmente se observavam pseudo-inclusões em consequiência de invaginações proeminentes da membrana nuclear (Fig. 12). Nas áreas onde havia marcada degeneração dos hepatócitos, o citoplasma das células de Kupffer exibia numerosos lisossomos contendo lipofuscina-ceróide. $\mathrm{O}$ citoplasma das células de alguns ductos estava vacuolizado (Fig. 11).

No epitélio dos tubos contorcidos proximais do rim foram observados edema das células, tumefação das mitocôndrias com desorganização e ruptura das cristas e matriz finamente granular e gotículas de gordura no citoplasma (Fig. 13-15). Em algumas células epiteliais havia ruptura das membranas mitocondriais. Lisossomos contendo material fortemente eletrodenso foram observados em muitas células tubulares. Alguns tinham forma circular, outros apresenta-

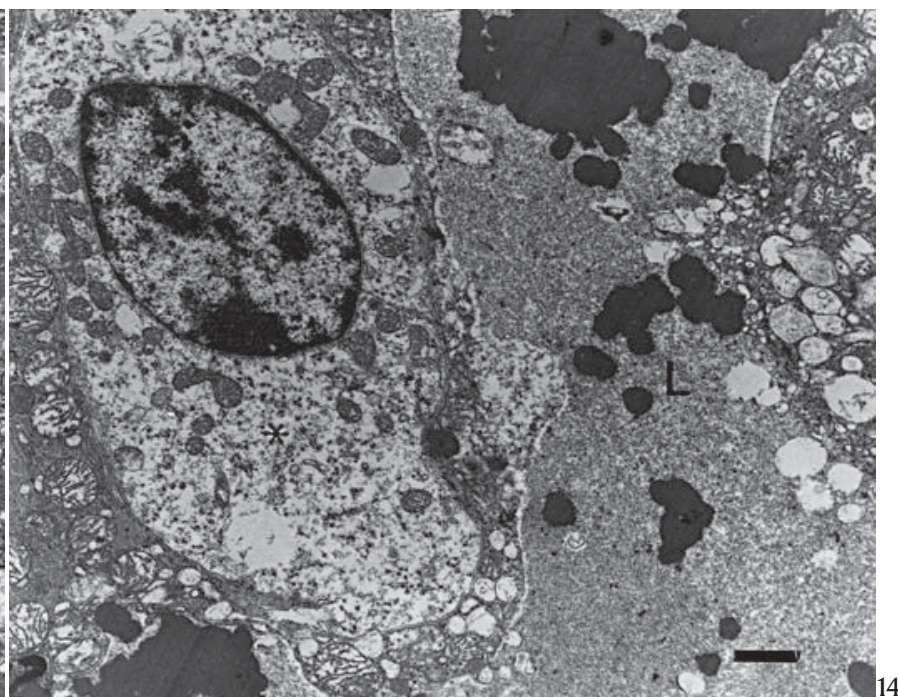

Fig. 13. Intoxicação espontânea por S. brasiliensis (Ovino 11). Ao alto, célula epitelial tubular renal com numerosas estruturas eletrodensas de contornos irregulares no citoplasma. Mitocôndrias com matriz finamente granular. Capilar intersticial com endotélio tumefeito ( $\left.{ }^{*}\right)$. Barra $=2 \mu \mathrm{m}$.

Fig. 14. Intoxicação espontânea por S. brasiliensis (Ovino 11). Rim. Túbulo contorcido proximal com estruturas eletrodensas na luz que corresponde à hemoglobina (L). Linfócito (") entre duas células tubulares. Barra $=1 \mu \mathrm{m}$.

Fig. 15. Intoxicação espontânea por S. brasiliensis (Ovino 11). Rim. No túbulo contorcido proximal à esquerda, há ruptura e desorganização das cristas mitocondriais e a matriz está granular. Alguns lisossomos contêm material eletrodenso. 0 túbulo à direita tem células atróficas e parede fina. Luz tubular (L). Bar$\mathrm{ra}=2 \mu \mathrm{m}$.

vam contornos irregulares (Fig. 13 e 15). Essas estruturas eletrodensas foram interpretadas como hemoglobina reabsorvida da luz tubular ou hemossiderina. Em alguns túbulos havia acentuada atrofia das células epiteliais. Essas eram reduzidas, em alguns pontos, a 5-6 mm de espessura. Estruturas fortemente eletrodensas de contornos irregulares (fragmentos de hemoglobina) foram também observadas na luz dos túbulos contornados (Fig. 14).

\section{Dosagem de cobre}

$\mathrm{O}$ resultado das dosagens de cobre no fígado e no rim dos animais afetados e dos controles consta no Quadro 3. O exame laboratorial de fragmentos de fígado e rim dos ovinos acometidos revelou níveis elevados de cobre que variavam de $369 \mathrm{ppm}$ a $1248 \mathrm{ppm}$ e $152 \mathrm{ppm}$ a $687 \mathrm{ppm}$ com base na matéria seca, respectivamente.

\section{DISCUSSÃO}

O diagnóstico da intoxicação por Senecio brasiliensis em ovinos neste estudo foi baseado nos dados epidemiológicos, nos 
sinais clínicos, nos achados de necropsia, nas alterações histopatológicas e nos resultados laboratoriais. O quadro clínico-patológico observado é semelhante ao descrito nas intoxicações espontânea e experimental por plantas que contêm pirrolizidinas em ovinos. $\mathrm{O}$ exame da pastagem onde esses animais eram mantidos revelou que $S$. brasiliensis, que apresentava sinais de ter sido ingerida, era a planta predominante e foi incriminada como a fonte de pirrolizidinas neste surto. Surtos de intoxicação por pirrolizidinas em ovinos não têm sido descritos no Rio Grande do Sul. Entretanto, $S$. brasiliensis já foi experimentalmente comprovada como tóxica para essa espécie animal (Barros et al. 1989).

A ação hepatotóxica das pirrolizidinas é responsável pelo desenvolvimento dos seguintes quadros clínico-patológicos em ovinos: (a) intoxicação primária por pirrolizidinas, de caráter agudo, associada à ingestão de doses elevadas de alcalóides durante um curto período de tempo, associada a necrose coagulativa hepatocelular massiva (Kellerman et al. 1988), (b) intoxicação primária por pirrolizidinas, de natureza crônica, causada pelo consumo de grandes quantidades de pirrolizidinas durante períodos prolongados, associada à fibrose hepática difusa e acentuada (Bull et al. 1968, Seaman 1985, 1987) e (c) intoxicação crônica hepatógena secundária por cobre $(\mathrm{Cu})$ associada ao acúmulo excessivo desse mineral no fígado (St George-Grambauer \& Rac 1962, Bull et al.1968, Seaman 1985, 1987). Em um mesmo rebanho de ovinos onde é diagnosticado um surto de intoxicação por plantas que contêm pirrolizidinas, as manifestações clínicas são variáveis e podem incluir fotossensibilização hepatógena, perturbações neurológicas (síndrome hepatocerebral), icterícia e hemoglobinúria (hemólise intravascular decorrente de níveis elevados de cobre no sangue) (St George-Grambauer \& Rac 1962, Bull et al. 1968, Seaman 1985, 1987). No presente surto, de forma semelhante, o espectro de sinais clínicos manifestados pelos ovinos afetados foi bastante amplo. O quadro clínico-patológico observado foi consistente com insuficiência hepática causada por fibrose. Adicionalmente, parte dos ovinos desenvolveram crises hemolíticas agudas fatais associadas à liberação abrupta do cobre armazenado no fígado para a circulação sangüínea. Esses sinais clínicos podem ser confundidos com os de outras enfermidades que afetam ovinos de modo que os dados epidemiológicos foram essenciais para o diagnóstico da doença neste surto.

Ovinos são considerados os animais mais susceptíveis aos efeitos tóxicos do cobre. A intoxicação por cobre nessa espécie pode ocorrer sob as seguintes formas: (a) forma aguda que ocorre pela ingestão de doses elevadas de $\mathrm{Cu}$; (b) forma crônica primária causada pelo consumo de alimentos contendo níveis elevados de cobre; (c) intoxicação crônica fitógena associada ao consumo de pastagens que contêm níveis normais de $\mathrm{Cu}$ e teores reduzidos de molibdênio e (d) intoxicação crônica hepatógena em que o acúmulo de $\mathrm{Cu}$ ocorre em conseqüiência de lesões hepáticas causadas por plantas que contêm pirrolizidinas (Seaman 1987, Kelly 1993, Pereira \& Rivero 1993). No Rio Grande do Sul, surtos de intoxicação crônica por Cu em ovinos são freqüientes e geralmente estão associados à ingestão excessiva desse elemento atra- vés da suplementação alimentar a base de concentrados $(\mathrm{Ri}-$ beiro et al. 1985a, Riet-Correa et al. 1989, Pilati et al. 1990). Essa é a forma mais comum da toxicose diagnosticada em nosso estado. Mesmo as rações formuladas especialmente para ovinos possuem níveis elevados de $\mathrm{Cu}$, o que favorece a ocorrência dessa forma de intoxicação (Riet-Correa et al. 1989). Surtos da toxicose associados à ingestão de quantidades excessivas de $\mathrm{Cu}$ em pastagem aspergida com sulfato de Cu (Ribeiro et al. 1995) e casos de intoxicação fítógena provocadas pelo consumo de pastagens contendo níveis baixos de molibdênio (Vasconcelos s/d) também têm sido descritos em nossa região. Entretanto, a forma crônica hepatógena da intoxicação associada a lesões hepáticas causadas por pirrolizidinas, observadas em parte dos ovinos no surto aqui descrito, não tem sido relatada no país.

Em surtos de intoxicação por plantas contendo pirrolizidinas, por exemplo, Echium plantagineum, a maior parte dos ovinos afetados corresponde a animais mais velhos (St GeorgeGrambauer \& Rac 1961). Sugere-se que a faixa etária dos ovinos tem influência sobre a ocorrência dessa enfermidade. Animais de idade mais avançada são mais predispostos ao desenvolvimento de lesões hepáticas de caráter crônico associadas ao consumo de pirrolizidinas. Essa categoria animal permanece por maior período de tempo em pastagens infestadas por plantas contendo pirrolizidinas ingerindo maior quantidade destas (St George-Grambauer \& Rac 1961, Seaman 1985). Na Austrália, a intoxicação por Heliotropium spp e $E$. plantagineum em ovinos geralmente ocorre no segundo ou terceiro ano de permanência desses animais em campos invadidos pela planta (St George-Grambauer \& Rac 1961, Bull et al. 1968, Seaman 1985, Seaman et al. 1989). Experimentalmente, observa-se que ovinos mantidos por duas a três estações consecutivas em pastagens contendo Heliotropium europaeum adoecem e morrem principalmente a partir do segundo ano de pastoreio nesses piquetes. Em geral, no primeiro ano não há mortes ou a taxa de mortalidade é baixa (até $8 \%$ ), enquanto que no segundo ano essa taxa chega a 70\% (Bull et al. 1968). Em nossos casos, a maior parte dos ovinos afetados tinha até dois anos de idade. Estes dados diferem dos descritos na literatura. No surto aqui descrito, não havia históricos de que os ovinos tivessem permanecido em pastagens infestadas por $S$. brasiliensis em anos anteriores. A escassez de dados a esse respeito dificulta o estabelecimento de uma correlação inequívoca entre as lesões hepáticas observadas naqueles ovinos mais velhos (acima de 2 anos) e o consumo da planta em estações sucessivas. Sugere-se que em nossos casos não houve o consumo da planta em anos anteriores uma vez que a maioria dos ovinos afetados correspondia a ovinos jovens, ou seja, àqueles animais de até 1 ano (100\%) ou com idades que variavam de 1 a 2 anos $(54,28 \%)$. Surtos de intoxicação por plantas que contêm pirrolizidinas, tais como E. plantagineum (St George-Grambauer \& Rac 1961), S. cineraria (Forsyth 1979) e $S$. sanguisorbae (Rosiles \& Paasch 1982), têm sido descritos em ovinos colocados por apenas uma estação em áreas altamente infestadas por essas plantas (St GeorgeGrambauer \& Rac 1961, Forsyth 1979, Rosiles \& Paasch 1982). Condição epidemiológica semelhante foi observada no surto 
de intoxicação por $S$. brasiliensis em ovinos descrito neste relato.

No Rio Grande do Sul, o combate de S. brasiliensis através do pastoreio de ovinos em potreiros altamente infestados pela planta é um procedimento bem sucedido e seguro nos casos em que a lotação de 20 ovinos por hectare é empregada durante um período de 30 dias (Soares et al. 2000). Neste surto, as lotações de ovinos nos três piquetes dessa propriedade, severamente invadidos por $S$. brasiliensis variavam de 1,3 a 3,76 ovinos por hectare. Apesar da reconhecida resistência dos pequenos ruminantes aos efeitos hepatotóxicos das pirrolizidinas (Dollahite 1972), a combinação de uma série de condições epidemiológicas particulares contribuíram de forma decisiva para a ocorrência de um número elevado de casos de intoxicação por $S$. brasiliensis neste estabelecimento. Essas condições incluíram: (a) grande quantidade de S. brasiliensis nos potreiros; (b) número reduzido de ovinos que pastavam nesses potreiros; (c) longo período de tempo em que os animais foram mantidos nessas áreas (aprox. 7 meses) e (d) fome.

Crises hemolíticas agudas associadas à intoxicação hepatógena por cobre têm sido apontadas como uma das principais causas de morte em ovinos intoxicados por pirrolizidinas (St George-Grambauer \& Rac 1962, Bull et al. 1968, Seaman 1985, 1987). No surto aqui descrito, os Ovinos 1, 2, 5, 9 e 11 apresentaram hemólise, nefrose hemoglo-binúrica e icterícia acompanhada, em alguns dos animais, de níveis elevados de cobre no fígado e nos rins. Esses achados são consistentes com essa forma de intoxicação por cobre. Sugere-se que, nessas situações, os níveis de cobre disponíveis na alimentação estão discretamente elevados. $\mathrm{O}$ arma-zenamento de grande quantidade desse elemento no fígado de ovelhas é favorecido pela lesão provocada pelas pirro-lizidinas (Howell et al. 1991).

Mortes de ovinos devido a crises hemolíticas agudas têm sido observadas em experimentos a campo em que rebanhos de ovinos são mantidos em pastagens de $H$. europaeum e recebem suplementação adicional de cobre na dieta. Nessa situação, a taxa de mortalidade varia de 33\% a 63\% (Bull et al. 1968). Estudos experimentais em ovelhas estabuladas revelaram que aqueles animais que receberam exclusivamente $H$. europaeum desenvolveram apenas lesões hepáticas típicas da intoxicação por pirrolizidinas. Todavia, não houve o acúmulo de grande quantidade de $\mathrm{Cu}$ no fígado desse grupo de ovinos, uma vez que não havia fonte suplementar desse mineral na alimentação. Por outro lado, a administração simultânea de $H$. europaeum e de cobre ou a administração dessa planta seguida da suplementação por Cu após 8 semanas provocou a acumulação de níveis tóxicos de cobre no fígado, superiores àqueles observados nos casos em que foi administrado somente o cobre aos ovinos do experimento (Howell et al. 1991). Esses estudos estão em desacordo com experimentos de mesma natureza envolvendo a administração de $S$. jacobae para ovinos. Nestes últimos, a ingestão de $S$. jacobae produziu um quadro clínico-patológico consistente com a intoxicação crônica por pirrolizidinas. No entanto, não foram verificadas concentrações elevadas de Cu nem lesões típicas de intoxicação crônica por esse elemento mesmo na presen- ça de grande quantidade de cobre na dieta dos animais do experimento (White et al. 1984).

Tem sido sugerido que uma condição essencial para a ocorrência da intoxicação hepatógena por $\mathrm{Cu}$ associada à ingestão de pirrolizidinas em ovinos é a presença de uma fonte adicional desse mineral. Esse elemento pode ser ingerido simultaneamente com plantas que contêm pirrolizidinas ou algum tempo (de algumas semanas a meses) após a ingestão dessas. Nessas condições, as lesões hepáticas induzidas pela ação das pirrolizidinas - fibrose hepática, hepatomegalocitose e hiperplasia ductal - predispõem ao maior acúmulo de Cu no fígado desses ovinos em relação a outros animais que ingerem a mesma quantidade de Cu mas não apresentam lesão hepática dessa natureza (Howell et al. 1991). O mecanismo patogenético pelo qual as pirrolizidinas promovem acúmulo excessivo de Cu no fígado não está completamente esclarecido (Cheeke 1992). A intoxicação crônica por $\mathrm{Cu}$ associada à toxicose por pirrolizidinas, de forma semelhante ao que tem sido observado na toxicose por fomopsina (substância produzida pelo fungo Phomopsis leptostromiformis, parasita de plantas do gênero Lupinus) tem sido relacionada ao papel crítico que a mitose hepatocelular desempenha na ovelha em retardar o início da crise hemolítica. Qualquer agente capaz de interferir com a mitose dos hepatócitos poderia provocar a crise hemolítica em estágios iniciais do acúmulo de cobre (Kelly 1993). O acúmulo de Cu hepático na intoxicação por pirrolizidinas não ocorre somente na espécie ovina. Níveis hepáticos elevados de $\mathrm{Cu}$ associados à intoxicação por pirrolizidinas também já foram observados em cavalos, coelhos e ratos (Cheeke 1992). Assim, níveis de Cu um pouco acima daqueles recomendados para a nutrição de ovinos mas que não são suficientes para induzir um quadro de intoxicação crônica por cobre em animais saudáveis, mesmo quando há aumento considerável das concentrações hepáticas desse elemento, podem induzir a forma hepatógena da doença em ovinos que apresentam lesões hepáticas produzidas por pirrolizidinas.

Na Austrália, em experimentos a campo com ovinos onde havia grande quantidade de E. plantagineum, esses animais desenvolveram lesões histológicas típicas da intoxicação crônica por pirrolizidinas e aumento nos níveis de cobre no fígado. Observou-se que essa planta apresentava níveis elevados de cobre e baixos teores de molibdênio. O quociente Cobre (Cu):Molibdênio (Mo) de E. plantagineum nesse estudo era de 41 a 47 em média (Seaman et al. 1989). As demais pastagens utilizadas na alimentação desses animais apresentavam quocientes médios de Cu:Mo de 15 a 18. Pastagens com quocientes Cu:Mo maiores que 10:1 oferecem riscos para ovinos, particularmente para aqueles mais susceptíveis ao desenvolvimento dessa condição, i. e., aqueles que apresentam lesões hepáticas causadas pelo consumo de plantas que contêm pirrolizidinas (Seaman et al. 1989, Seaman \& Dixon 1989). Em um experimento semelhante com $H$. europaeum, essa planta apresentava um quociente Cu:Mo de 10,2 e as demais pastagens da mesma área tinham entre 5,4 a 29,2 de Cu:Mo (Peterson et al. 1992). Entretanto, nesse estudo, as concentrações de $\mathrm{Cu}$ no fígado dos ovinos não estavam elevadas 
(Peterson et al. 1992). Isso corrobora a hipótese de que o teor elevado de cobre é uma condição necessária para a ocorrência de intoxicação hepatógena crônica em ovinos associada à ingestão de pirrolizidinas.

Na primavera, as pastagens nativas do Rio Grande do Sul contêm níveis de Cu entre 5,6 a 9,9 ppm e níveis Mo abaixo de $1 \mathrm{ppm}$. No verão, os níveis de Cu tendem a diminuir. Nesse estado, a média dos quocientes Cu:Mo é de aproximadamente 40:1 na primavera. As proporções de Cu: Mo estão elevadas em decorrência de níveis baixos de Mo. No entanto, há grande variação na relação Cu:Mo entre as amostras de plantas obtidas nas diferentes regiões do Estado (Gavillon \& Quadros 1976). No presente estudo, não foram realizadas dosagens de cobre e molibdênio na pastagem nativa e em $S$. brasiliensis presentes dos potreiros onde estavam os ovinos. Entretanto, nos municípios vizinhos à cidade onde ocorreu o surto (Mata), por ex., São Vicente do Sul, São Pedro do Sul e Tupanciretã, sabe-se que a relação $\mathrm{Cu}$ :Mo nas pastagens varia entre 11,8 a 49,3 (Gavillon \& Quadros 1976). Acredita-se que a relação $\mathrm{Cu}$ :Mo possa ter influenciado na intoxicação hepatógena crônica por cobre neste caso, embora dados a esse respeito não estejam disponíveis para a região onde ocorreu o surto. Deve ser salientado que os resultados das análises minerais do solo e da pastagem devem ser interpretados com cautela. Nesses casos, sugere-se o estudo conjunto desses elementos em amostras de pasto, solo e no fígado e rim de animais que estão alocados nessas regiões. Crises hemolíticas agudas fatais foram observadas em ovinos intoxicados experimentalmente por $S$. brasiliensis (Barros et al. 1989). Deve ser ressaltado que, durante esse experimento, os animais recebiam, além da planta tóxica, feno de alfafa e ração comercial que constituia a fonte adicional de cobre.

No presente surto, nódulos de regeneração foram observados no fígado de cinco ovinos. Na Austrália, essas lesões também têm sido encontradas à necropsia ou na inspeção em frigoríficos no fígado de ovelhas que foram mantidos em pastagens contendo H. europaeum por tempo prolongado (Bull et al. 1968, Peterson et al. 1992). O exame histológico dessas lesões revelou grande variação na quantidade de focos de regeneração do parênquima hepático. Havia desde alguns raros nódulos regenerativos até a completa substituição de um ou mais lóbulos hepáticos que tinham arquitetura bastante diversa das dos lóbulos hepáticos inalterados. Adicionalmente, os hepatócitos que formavam esses nódulos geralmente não apresentavam alterações no tamanho e conformação do núcleo e dimensões do citoplasma e foram observadas algumas figuras de mitose em hepatócitos apenas ocasionalmente (Peterson et al. 1992). Achados semelhantes foram encontrados nos ovinos deste estudo.

Hepatomegalocitose, caracterizada por aumento do tamanho dos núcleos dos hepatócitos (cariomegalia) e aumento de volume do citoplasma das células hepáticas, é a alteração histológica tipicamente observada na intoxicação por plantas que contêm alcalóides pirrolizidínicos (Bull et al. 1968). Cariomegalia hepatocelular também tem sido descrita na intoxicação crônica por Cu em ovinos (Bostwick 1982, Kellerman et al. 1988, Riet-Correa et al. 1989). No entanto, alterações nas dimensões do citoplasma dos hepatócitos não têm sido observadas na intoxicação crônica por Cu. Em estudos experimentais em ovinos que receberam $H$. europaeum e $\mathrm{Cu}$, administrados em separado ou simultaneamente, foi observado cariomegalia dos hepatócitos em todos os grupos de animais tratados. Todavia, megalocitose foi observada somente nos grupos que receberam exclusivamente $H$. europaeum e naqueles dosados com $\mathrm{H}$. europaeum e $\mathrm{Cu}$ (Howell et al. 1991). Hepatomegalocitose foi um achado histopatológico consistemente observado no fígado dos ovinos afetados neste surto. Esta lesão histológica foi atribuída à ingestão de pirrolizidinas presentes em $S$. brasiliensis.

No presente surto, fotossensibilização hepatógena foi observada na maior parte dos ovinos. De forma similar, lesões de fotodermatite têm sido descritas na intoxicação espontânea por plantas contendo pirrolizidinas em ovinos (Seaman 1987) e em experimentos a campo com H. europaeum nessa espécie animal (Bull et al. 1968, Peterson et al. 1992). Fotossensibilização hepatógena, associada a diferentes etiologias, tem sido atribuída à retenção de filoeritrina, pigmento derivado da clorofila, a partir da ação desdobradora dos microorganismos dos pré-estômagos. A filoeritrina usualmente é eliminada na bile. Nos casos em que há lesões hepáticas e que provocam lesões hepáticas difusas e acentuadas, de caráter agudo, subagudo ou crônico, esse pigmento fotossensibilizante fica retido na circulação sangüínea e se acumula na pele tornando-a mais sensível à ação dos raios solares (Tokarnia et al. 2000). Esse mecanismo patogenético também se aplica aos casos de fotodermatite observados nos ovinos deste surto.

Perturbações neurológicas associadas à degeneração esponjosa do encéfalo e medula espinhal estão associadas à encefalopatia hepática (síndrome hepatocerebral). A patogenia dessas lesões é multifatorial e envolve o acúmulo de diversas substâncias tóxicas na corrente sangüínea, tais como a amônia, ácidos graxos de cadeias curtas e mercaptanos no encéfalo e no líquor, além de alterações nas concentrações de neurotransmissores. Entretanto, a amônia é considerada como a substância mais importante na patogênese da encefalopatia hepática (Kellerman et al. 1988). Essa hipótese tem sido fortalecida por experimentos em que a infusão intravenosa de acetato de amônia em ovinos induziu o aparecimento de alterações espongiformes no encéfalo em um período de três dias (Hooper 1975). De forma similar, necrose hepática acentuada e difusa induzida experimentalmente por pirrolizidinas em ovinos provoca degeneração esponjosa no sistema nervoso central e aumento nos níveis de amônia no sangue e de glutamina no líquido cefalorraquidiano, um produto do metabolismo da amônia no encéfalo (Hooper et al. 1974). A degeneração esponjosa (status spongiosus) é mais pronunciada na substância branca do mesencéfalo, base do encéfalo, nos pedúnculos cerebelares e na junção entre substância branca e cinzenta (Kellerman et al. 1988). Neste surto, em todos os casos em que o encéfalo dos ovinos foi sistematicamente examinado na histologia (Ovinos 1, 2, 5, 9, 11, 12, 46, 115 e 136), foi observada degeneração esponjosa da substância branca do encéfalo. 
As alterações ultra-estruturais observadas no fígado dos ovinos deste surto são semelhantes às descritas na intoxicação experimental por Cu nessa espécie (Kumartilake \& Howell 1989). Há uma correlação positiva entre o número e tamanho dos lisossomos hepatocelulares e os níveis de Cu nessas células. Lisossomos aumentados de volume e de forma irregular são o resultado da fusão de várias dessas organelas contendo cobre (Kumartilake \& Howell 1989). As estruturas eletrodensas observadas nas células epiteliais dos túbulos renais correspondem a lisossomos distendidos por proteína que está sendo degradada para retornar à circulação sob a forma de aminoácidos (Barros 2001). Nos casos aqui descritos, essa proteína correspondia à hemoglobina.

Em vários surtos de intoxicação crônica por $\mathrm{Cu}$ em ovinos, níveis de $\mathrm{Cu}$ no rim e no fígado são utilizados como método auxiliar para o diagnóstico (Pilati et al. 1990, RietCorrea et al. 1989, MacPherson et al. 1997, Brooks 1998). Muitos autores acreditam que a concentração de $\mathrm{Cu}$ no fígado é o indicador mais sensível da exposição de ruminantes a dietas com altos níveis de Cu (Auza et al. 1999). Os níveis de cobre dos ovinos que desenvolveram crise hemolítica neste surto variaram de 369 a $854 \mathrm{ppm}$ com base na matéria seca (MS) no fígado e 152 a $679 \mathrm{ppm}$ MS no rim. Níveis de cobre iguais ou superiores a $500 \mathrm{ppm}$ MS no fígado e $80 \mathrm{ppm}$ MS no rim indicam ocorrência de intoxicação por esse mineral (Pope 1971). No entanto, níveis baixos de Cu no fígado (247 ppm MS) já foram observados em casos de intoxicação por Cu em ovinos (Case 1974). A determinação do Cu no córtex renal é o procedimento mais confiável para o diagnóstico de intoxicação por $\mathrm{Cu}$ em ovinos (Pope 1971) uma vez que após a crise hemolítica os valores de Cu hepático tendem a decrescer (Gooneratne et al. 1979).

Em dois animais (Ovinos 46 e 115), que não desenvolveram crise hemolítica, os níveis de cobre hepático estavam acima de 1.000 ppm MS. Níveis semelhantes também são observados em animais mantidos em pastagens contaminadas com $\mathrm{H}$. europaeum (Bull et al. 1968). Em experimentos a campo com $H$. europaeum, de $78 \%$ a $100 \%$ dos animais que morrem apresentam níveis hepáticos superiores a 1.000 ppm MS. No entanto somente $40 \%$ dessas mortes são atribuídas à crise hemolítica (Bull et al. 1968). O conteúdo de cobre no fígado pode variar de $5 \mathrm{ppm}$ MS em cordeiros a aproximadamente $1.000 \mathrm{ppm}$ MS em algumas ovelhas adultas, clinicamente normais que tenham consumido alimentação contendo altos níveis de cobre (Case 1974, Kerr \& McGavin 1991). Níveis elevados de Cu não são diagnósticos para intoxicação crônica por esse elemento, mas são indicativos de que esse animal está sob risco de desenvolvimento dessa condição caso o Cu venha a ser liberado na corrente sanguínea (Kellerman et al. 1988). Os níveis altos de Cu hepático ofereciam um risco potencial para o desenvolvimento de crise hemolítica nos Ovinos 46 e 115 deste estudo. Entretanto, esses animais morreram de insuficiência hepática devido à intoxicação crônica por pirrolizidinas. É possível que a mudança de alimentação desses animais ao serem transferidos da pastagem original para o HV diminui a disponibilidade de Cu da dieta evitando o acúmulo de quantidades ainda maiores desse mineral no fígado dos ovinos.
As concentrações de $\mathrm{Cu}$ no rim de todos os animais analisados estavam acima dos valores normais inclusive nos animais que não desenvolveram crise hemolítica e nos ovinos controles. Níveis de $\mathrm{Cu}$ em ovinos experimentais de grupos que receberam $\mathrm{Cu}$ e $\mathrm{H}$. europaeum separadamente estavam um pouco acima dos teores desse mineral nos controles, enquanto que nos ovinos do grupo que recebeu as duas substâncias simultaneamente, os níveis de Cu renais estavam mais elevados (Howell et al. 1991). Fato semelhante ocorreu neste surto. Cabe ressaltar que, mesmo em países desenvolvidos, poucos laboratórios realizam análises quantitativas fidedignas de Cu nos tecidos (Johnson et al. 1984). Os resultados das análises dos níveis hepáticos e renais obtidos nestes ovinos podem estar equivocados devido a erros no acondicionamento, processamento e análise do material. Comparandose a dosagem de $\mathrm{Cu}$ hepático com a coloração de rodanina do fígado do Ovino 9, observa-se que não há correlação entre os resultados obtidos a partir do exame químico e histológico desse material. O fígado do Ovino 9 foi fortemente positivo na coloração de Rodanina, ao passo que os valores de $\mathrm{Cu}$ hepático estavam baixos na análise química. O corante rodanina empregado na demostração de Cu reage especificamente tanto com o cobre cúprico quanto com o cobre cuproso produzindo um precipitado vermelho nos fígados fixados em formol e emblocados em parafina. Um estudo comparativo de biópsias de fígado de cães Bedlington terriers em que foi feita a quantificação de cobre hepático através da coloração de Rodanina demonstrou que esse procedimento é suficientemente confiável para estimação semiquantitativa de cobre hepático para o diagnóstico de toxicose nessa espécie (Johnson et al. 1984).

Os sinais clínicos observados na intoxicação crônica por S. brasiliesis em ovinos não são específicos, mas comuns a várias doenças, de etiologias diversas, que causam lesão hepática difusa e acentuada provocando insuficiência hepática. Em nosso meio, devem ser consideradas principalmente as enfermidades de etiologia tóxica que afetam ovinos, tais como a intoxicação por plantas que contêm alcalóides pirrolizidínicos. As plantas hepatotóxicas que ocorrem na Região Sul do Brasil que, em condições naturais, causam um quadro clínico-patológico semelhante à intoxicação crônica por $S$. brasiliensis incluem outras espécies de Senecio, E. plantagineum e Crotalaria spp. Nesta região do país, a distribuição, os diferentes habitat e a ocorrência sazonal dessas plantas permite que, na maior parte dos casos, o diagnóstico diferencial da toxicose por $S$. brasiliensis seja feito sem dificuldades. Também devem ser considerada a intoxicação por plantas que provocam quadros de fotossensibilização primária ou fotossensibilização secundária (hepatógena) acompanhada de icterícia como Lantana spp, Brachiaria decumbens, B. brizantha, Myoporum laetum (Méndez 1993b, Tokarnia et al. 2000, Seitz et al. 2001). Fagopyrum esculentum é uma planta tóxica que provoca fotossensibilização primária em ovinos em outras regiões do Mundo (Tokarnia et al. 2000) e também é encontrada em algumas áreas da Região Sul do Brasil. No entanto, não há registros da intoxicação espontânea por essa planta em animais de fazenda do Brasil até o presente momento. 
Adicionalmente, uma forma rara de fotossensibili-zação de caráter congênito tem sido descrita em ovinos das raças Corriedale e Southdown (Radostits et al. 1994). Desconhecese a prevalência dessa doença hereditária em rebanhos ovinos em nosso país.

Doenças que usualmente cursam com marcada icterícia e hemoglobinúria também devem ser incluídas no diagnóstico diferencial da intoxicação por $S$. brasiliensis em ovinos que é complicada por crises hemolíticas agudas fatais. Devem ser consideradas as seguintes formas de intoxicação por cobre nessa espécie animal: (a) forma aguda; (b) forma crônica primária e (c) intoxicação crônica fitógena. Enfermidades de menor importância ou de ocorrência esporádica em ovinos que causam icterícia e hemoglobinúria devem ser consideradas no diagnóstico diferencial da intoxicação crônica por $S$. brasiliensis nessa espécie animal. Essas incluem a leptospirose, doença negra [hemoglobinúria bacilar causada por Clostridium haemolyticum (C. novyi tipo D)] e hemoglobinúria pós-parto. Algumas dessas doenças ainda não foram diagnosticadas no Brasil em ovinos ou foram diagnosticadas em uma única ocasião (Ribeiro et al. 1985b, Radostits et al. 1994).

Prejuízos econômicos experimentados pelos criadores em função do emprego de ovinos no controle e erradicação de espécies de Senecio das pastagens nativas no Rio Grande do Sul não se limitam apenas às perdas por mortes de animais como observado em nosso surto. Na Austrália, além das mortes de ovinos atribuídas ao consumo de $H$. europaeum e $E$. plantagineum, perdas econômicas significativas também ocorrem por redução do potencial produtivo do rebanho ovino devido à lesão hepática crônica induzida pelas pirrolizidinas. A vida produtiva de ovelhas que consomem $H$. europaeum pode ser reduzida drasticamente - de 8 anos para 5-6 anos. Em experimentos a campo com E. plantagineum em ovinos, mesmo que não ocorram mortes, os animais que desenvolvem lesões histológicas hepáticas típicas da intoxicação por pirrolizidinas apresentam emagrecimento progressivo, menor ganho de peso e diminuição do crescimento da lã (Seaman 1987, Seaman \& Dixon 1989, Seaman et al. 1989). Um estudo histológico sistemático do fígado de ovinos que pastoreiam em campos infestados por $S$. brasiliensis através de biópsias ou durante o abate desses animais em nossa região talvez fosse aconselhável.

\section{REFERÊNCIAS}

Auza N.J., Olson W.G., Murphy M.J. \& Linn J.G. 1999.Diagnosis and treatment of copper toxicosis in ruminants. J. Am. Vet. Med. Assoc. 214: 1624-1628.

Barros C.S.L. 2001. Intoxicação por Amaranthus sp. em bovinos. Anais do $10^{\circ}$ Econtro Nacional de Patologia Veterinária, Pirrassununga, SP. Patologia das Intoxicações - Fórum de lâminas, caso n 26, p. 264-266.

Barros C.S.L., Driemeier D., Pilati C. \& Barros S.S. 1992. Senecio spp. poisoning in cattle in Southern Brazil. Vet. Human Toxicol. 34: 241-246.

Barros C.S.L., Metzdorf L.L., Santos, M.N., Barros, S.S. \& Peixoto, P.V. 1989. Intoxicação experimental por Senecio brasiliensis (Compositae) em ovinos. Pesq. Vet. Bras. 9: 55-67.

Bostwick J.L. 1982. Copper toxicosis in sheep. J. Am. Vet. Med. Assoc. 180: 386-387.

Brooks G. 1998. Copper poisoning in ewes. Vet. Rec. 142: 24
Bull L.B., Culvenor C.C.J. \& Dick A.T. 1968. The pirrolizidine alkaloids: Their chemistry, pathogenicity and other biological properties. North-Holland Publ. Co., Amsterdam. 293 p.

Case A.A. 1974. Toxicity of various chemical agents to sheep. J. Am. Vet. Med. Assoc. 164: 277-283.

Cheeke P.R. 1992. Copper, vitamin A, and pyrrolizidine alkaloid interactions in livestock and laboratory animals, p. 175-180. In: James L.F., Keeler R.F., Bailey Jr. E.M., Cheeke P.R. \& Hegarty M.P. Proc. $3^{\text {rd }}$ International Symposium of Poisonous Plants, Logan, Utah, 1988. Iowa State University Press, Ames:

Craig A.M., Latham C.J., Blythe L.L., Schmotzer W.B. \& O'Connor O.A. 1992. Metabolism of toxic pyrrolizidine alkaloids from tansy ragwort (Senecio jacobaea) in ovine ruminal fluid under anaerobic conditions. Appl. Environ. Microbiol. 58: 2730- 2736.

Dollahite J.W. 1972. The use of sheep and goats to control Senecio poisoning in cattle. Southwest. Vet. 25: 223-226.

Forsyth A.A. 1979. British Poisonous Plants. $2^{\text {nd }}$ ed. $5^{\text {th }}$. Impr. Bull. 161, Ministry Agric., Fish and Food, London, p. 98-102.

Gavillon O. \& Quadros A.T.F. 1976. O cobre, o molibdênio e o sulfato inorgânico em pastagens nativas no Rio Grande do Sul. Anuário Técnico IPZFO 3: 423453.

Gooneratne S.R., Howell J. McC. \& Gawthorne J. 1979. Intracellular distribution of copper in the liver of normal and copper loaded sheep. Res. Vet. Sci. 27: 30-37.

Hooper P.T. 1975. Spongy degeneration in the central nervous system of domestic animals. Part III: Occurrence and pathogenesis of hepatocerebral disease caused by hyperammonaemia. Acta Neuropathologia (Berlin) 31: 343- 351

Hooper P.T., Best S.M. \& Murray D.R. 1974. Hyperammonaemia and spongy degeneration of the brain in sheep affected with hepatic necrosis. Res. Vet. Sci. 16: 216-222.

Howell J. McC., Deol H.S., Dorling P.R. \& Thomas J.B. 1991. Experimental copper and heliotrope intoxication in sheep: Morphological changes. J Comp. Path. 105: 49-74.

Huan J., Miranda C.L., Buhler D R. \& Cheeke P.R. 1998. Species differences in the hepatic microsomal enzyme metabolism of the pyrrolizidine alkaloids. Toxicology Letters 99: 127-137.

Johnson G. F., Gilbertson S. R., Goldfisher S., Grushoff P. S. \& Sternlieb I. 1984.Cytochemical detection of inherited copper toxicosis of Bedlington Terriers. Vet. Path. 21: 57-60.

Jonhston W.H., Craig A.M., Blythe L.L., Hovermale J.T. \& Walker K. 1998. Pyrrolizidine alkaloid detoxification by an ovine ruminal consortium and its use as a ruminal supplement in cattle, p. 185-190. In: Garland T. \& Barr A.C. Toxic Plants and other Natural Toxicants. CAB International, Oxon.

Kellerman T.S., Coetzer J.A.W. \& Naudé T.W. 1988. Plant Poisonings and Mycotoxicoses of Livestock in Southern Africa. Oxford University Press, Cape Town. 243p.

Kelly W.R. 1993. The liver and biliary system, p. 319-406. In: Jubb K.V.F. \& Kennedy P.C., Palmer N. (ed.) Pathology of Domestic Animals. Vol. 2. $4^{\text {th }}$ ed. Academic Press, San Diego. 747p.

Kerr L.A. \& McGavin H.D. 1991.Chronic copper poisoning in sheep grazing pastures fertilized with swine manure. J. Am. Vet. Med. Assoc. 198: 99-101.

Klitzke C.F. \& Trigo J.R. 2000. New records of pyrrolizidine alkaloid-feeding insects. Hemiptera and Coleoptera on Senecio brasiliensis. Biochemical Systematics and Ecology, 28: 313-318.

Kumaratilake J.S. \& Howell J. McC. 1989. Lysosomes in the pathogenesis of liver injury in chronic copper poisoned sheep: an ultrastructural and morphometric study. J. Comp. Path. 10: 381-390.

MacPherson A., Milne E.M. \& MacPherson A. J. 1997. Copper poisoning in ewes. Vet. Rec. 141: 631.

Méndez M.C. 1993a. Intoxicação por Senecio spp., p. 43-57. In: Riet-Correa, F., Méndez, M.C. \& Schild, A.L. (ed.) Intoxicações por Plantas e Micotoxicoses em Animais Domésticos. Editora Hemisfério Sul do Brasil, Pelotas. 340p.

Méndez M.C. 1993b. Intoxicação por Myoporum spp., p. 79-84. In: Riet-Correa 
F, Méndez M.C. \& Schild A.L. (ed.) Intoxicações por Plantas e Micotoxicoses em Animais Domésticos. Editora Hemisfério Sul do Brasil, Pelotas. 340p.

Pereira D. \& Rivero R. 1993. Intoxicação crônica fitógena por cobre, p. 299307. In: Riet-Correa, F., Méndez, M.C. \& Schild, A.L. (ed.) Intoxicações por Plantas e Micotoxicoses em Animais Domésticos. Editora Hemisfério Sul do Brasil, Pelotas. 340 p.

Peterson J.E., Payne A.L. \& Culvenor C.C.J. 1992. Heliotropium europaeum poisoning of sheep with low liver copper concentrations and the preventive efficacy of cobalt and antimethanogen. Aust. Vet. J. 69: 51-56.

Pilati C., Barros C.S.L., Giudice J.C. \& Bondan E. 1990. Intoxicação crônica por cobre em ovinos. Hora Veterinária, Porto Alegre, 54: 31-34.

Pope A.L. 1971. A review of recent mineral research with sheep. J. Anim. Sci. 33: $1333-1343$.

Radostits O.M., Blood D.C. \& Gay C.C. 1994. Veterinary Medicine - a textbook of the diseases of cattle, sheep, pigs, goats and horses. 8th ed. Baillière Tindall, London. 1763p.

Ribeiro L.A.O., Neto J.A.S.P., Rodrigues N. \& Fallavena L.C.B. 1995. Intoxicação crônica por cobre em ovinos mantidos em pomar de macieiras. Pesq. Vet. Bras. 15:15-17.

Ribeiro L.A.O., Rodrigues N.C. \& Almeida D.S. 1985a. Hemoglobinúria pósparto em ovinos: relato de um caso. Anais do IX Congresso Estadual de Medicina Veterinária, Santa Maria, RS, p. 71. (Resumo)

Ribeiro L.A.O., Rodrigues N.C. \& Nardin N.S. 1985b. Intoxicação crônica pelo cobre em ovinos no Rio Grande do Sul: histopatologia e toxicologia. Anais do IX Congresso Estadual de Medicina Veterinária, Santa Maria, RS, p. 72. (Resumo)

Riet-Correa F., Oliveira J.A., Giesta S., Schild A.L. \& Méndez M.C. 1989. Intoxicação crônica por cobre em ovinos no Rio Grande do Sul. Pesq. Vet. Bras. 9:51-54.

Rosiles R. \& Paasch L.H. 1982. Megalocitosis hepática en ovinos. Veterinaria, México, 13:151-153.

Seaman J.T. \& Dixon R.J. 1989. Investigations into the toxicity of Echium plantagineum in sheep. 2. Pen feeding experiments. Aust. Vet. J. 66:286292.

Seaman J.T. 1985. Hepatogenous chronic copper poisoning in sheep associated with grazing Echium plantagineum. Aust. Vet. J. 62: 247-248.

Seaman J.T. 1987. Pyrrolizidine alkaloid poisoning of sheep in New South Wales. Aust. Vet. J. 64:164-167.

Seaman J.T., Turvey W.S., Ottaway S.J., Dixon R.J. \& Gilmour A.R. 1989. Investigations into the toxicity of Echium plantagineum in sheep. 1. Field grazing experiments. Aust. Vet. J. 66:279-285.

Seitz A.L., Traverso S.D., Loretti A.L., Bierhals G.S., Santos P.R.K., Gomar M.S, Krauspenhar C., Cattani C. \& Driemeier D. 2001. Ocorrência de fotossensibilização em ovinos mantidos em pastagem de Brachiaria decumbens no Rio Grande do Sul. Anais do X Encontro Nacional de Patologia Veterinária (Enapave). Pirrassununga, SP, p. 169. (Resumo)

Soares M.P., Riet-Correa F., Méndez M.C., Rosa F.G. \& Carreira E.G. 2000. Controle biológico de Senecio spp. com pastoreio de ovinos. Anais da II Reunión Argentina de Patologia Veterinária, Facultad de Ciências Veterinárias, Universidad Nacional Del Nordeste, Corrientes, Argentina, p. 79. (Resumo)

St. George-Grambauer T.D. \& Rac R. 1962. Hepatogenous chronic copper poisoning in sheep in South Australia due to the consumption of Echium plantagineum L. (Salvation jane). Aust. Vet. J. 45:288-293.

Tokarnia C.H., Döbereiner J. \& Peixoto P.V. 2000. Plantas Tóxicas do Brasil. Editora Helianthus, Rio de Janeiro. 310 p.

Vardiman P.H. 1952. Experimental feeding of Senecio silage to calves. J. Am. Vet. Med. Assoc. 121:397-400.

Vasconcelos R.O. s/d. Intoxicação crônica fitógena por cobre em ovinos. Seminário apresentado ao Programa de Pós-Graduação em Medicina Veterinária. 13 p.

White R.D., Swick R.A. \& Cheeke P.R. 1984. Effects of dietary copper and molybdenum on tansy ragwort (Senecio jacobaea) toxicity in sheep. Am. J Vet. Res. 45:159-161. 